Original article

\title{
Longitudinal changes in adherence to the portfolio and DASH dietary patterns and cardiometabolic risk factors in the PREDIMED-Plus study
}

Andrea J. Glenn a, b, c, Pablo Hernández-Alonso d, e, f , Cyril W.C. Kendall a, b, c, g, Miguel Ángel Martínez-González ${ }^{\mathrm{f}, \mathrm{h}, \mathrm{i}}$, Dolores Corella ${ }^{\mathrm{f}, \mathrm{j}}$, Montserrat Fitó ${ }^{\mathrm{f}, \mathrm{k}}$, J.Alfredo Martínez f, l, m , Ángel M. Alonso-Gómez f, n, Julia Wärnberg f, o, Jesús Vioque p, q, Dora Romaguera $^{\mathrm{f}, \mathrm{r}}$, José López-Miranda ${ }^{\mathrm{f}, \mathrm{s}}$, Ramon Estruch ${ }^{\mathrm{f}, \mathrm{t}}$, Francisco J. Tinahones ${ }^{\mathrm{f}, \mathrm{u}}$, José Lapetra $^{\mathrm{f}, \mathrm{v}}$, J. Luís Serra-Majem ${ }^{\mathrm{f}, \mathrm{w}}$, Aurora Bueno-Cavanillas ${ }^{\mathrm{p}, \mathrm{x}}$, Josep A. Tur ${ }^{\mathrm{f}, \mathrm{y}}$, Sofia Reguero Celada ${ }^{z}$, Xavier Pintó ${ }^{\text {, aa }}$, Miguel Delgado-Rodríguez ${ }^{\text {p, ab }}$, Pilar Matía-Martín ${ }^{\mathrm{ac}}$, Josep Vidal ad, ae, Sebastian Mas-Fontao ${ }^{\mathrm{f}}{ }^{\text {ad, af }}$, Lidia Daimiel $^{\mathrm{m}}$, Emilio Ros ${ }^{\text {f, ag }}$, David J.A. Jenkins ${ }^{\text {a, b, c, ai, aj, Estefania Toledo }}{ }^{\text {f, h }}$, José V. Sorlî ${ }^{\mathrm{f}, \mathrm{j}}$, Olga Castañer ${ }^{\mathrm{f}, \mathrm{k}}$, Itziar Abete ${ }^{\mathrm{f}, \mathrm{l}}$, Anai Moreno Rodriguez ${ }^{\mathrm{f}, \mathrm{n}}$, Olga Fernández Barceló ${ }^{\circ}$, Alejandro Oncina-Canovas ${ }^{\mathrm{q}}$, Jadwiga Konieczna ${ }^{\mathrm{f}, \mathrm{r}}$, Antonio Garcia-Rios ${ }^{\mathrm{f}, \mathrm{s}}$, Rosa Casas ${ }^{\mathrm{f}, \mathrm{t}}$, Ana Maria Gómez-Pérez ${ }^{\mathrm{f}, \mathrm{u}}$, José Manuel Santos-Lozano f, v, Zenaida Vazquez-Ruiz ${ }^{\mathrm{f}, \mathrm{h}}$, Olga Portolés ${ }^{\mathrm{f}, \mathrm{j}}$, Helmut Schröder ${ }^{\mathrm{k}, \mathrm{p}}$, Maria A. Zulet ${ }^{\mathrm{f}, \mathrm{l}}$, Sonia Eguaras ${ }^{\mathrm{f}, \mathrm{l} \text {, ah, }}$, Itziar Salaverria Lete ${ }^{\mathrm{f}, \mathrm{n}}$, María Dolores Zomeño k, ah , John L. Sievenpiper a, b, c, ai, aj, *, Jordi Salas-Salvadó d, e, f, **

a Department of Nutritional Sciences, Temerty Faculty of Medicine, University of Toronto, Toronto, Ontario, Canada

${ }^{\mathrm{b}}$ Clinical Nutrition and Risk Factor Modification Center, St. Michael's Hospital, Toronto, Ontario, Canada

${ }^{\text {c } T o r o n t o ~ 3 D ~ K n o w l e d g e ~ S y n t h e s i s ~ a n d ~ C l i n i c a l ~ T r i a l s ~ U n i t, ~ S t . ~ M i c h a e l ' s ~ H o s p i t a l, ~ T o r o n t o, ~ O n t a r i o, ~ C a n a d a ~}$

${ }^{\mathrm{d}}$ Universitat Rovira $\mathrm{i}$ Virgili, Departament de Bioquímica i Biotecnologia, Unitat de Nutrició, Reus, Spain

e University Hospital of Sant Joan de Reus, Nutrition Unit, Institut d'Investigació Sanitària Pere Virgili (IISPV), Reus, Spain

${ }^{\mathrm{f}}$ Centro de Investigación Biomédica en Red Fisiopatología de la Obesidad y la Nutrición (CIBEROBN), Instituto de Salud Carlos III, Madrid, Spain

g College of Pharmacy and Nutrition, University of Saskatchewan, Saskatoon, Saskatchewan, Canada

${ }^{\mathrm{h}}$ University of Navarra, Department of Preventive Medicine and Public Health, IdiSNA, Pamplona, Spain

i Department of Nutrition, Harvard T.H. Chan School of Public Health, Boston, MA, USA

${ }^{\mathrm{j}}$ Department of Preventive Medicine, University of Valencia, Valencia, Spain

${ }^{\mathrm{k}}$ Unit of Cardiovascular Risk and Nutrition, Institut Hospital del Mar de Investigaciones Médicas Municipal d Investigació Médica (IMIM), Barcelona, Spain

${ }^{1}$ Department of Nutrition, Food Sciences, and Physiology, Center for Nutrition Research, University of Navarra, IdiSNA, Pamplona, Spain

${ }^{\mathrm{m}}$ Nutritional Control of the Epigenome. IMDEA Food, CEI UAM + CSIC, Madrid, Spain

${ }^{n}$ Bioaraba Health Research Institute, Cardiovascular, Respiratory and Metabolic Area; Osakidetza Basque Health Service, Araba University Hospital; University of the Basque Country UPV/EHU, Vitoria-Gasteiz, Spain

${ }^{\circ}$ Department of Nursing. University of Málaga, Institute of Biomedical Research in Malaga (IBIMA), Málaga, Spain

p CIBER de Epidemiología y Salud Pública (CIBERESP), Instituto de Salud Carlos III, Madrid, Spain

q Instituto de Investigation Sanitaria y Biomédica de Alicante, ISABIAL-UMH, Alicante, Spain

${ }^{\mathrm{r}}$ Research Group on Nutritional Epidemiology \& Cardiovascular Physiopathology (NUTRECOR). Health Research Institute of the Balearic Islands (IdISBa), University Hospital Son Espases (HUSE), Palma de Mallorca, Spain

${ }^{s}$ Department of Internal Medicine, Maimonides Biomedical Research Institute of Cordoba (IMIBIC), Reina Sofia University Hospital, University of Cordoba, Cordoba, Spain

${ }^{\mathrm{t}}$ Department of Internal Medicine, Institut d'Investigacions Biomèdiques August Pi Sunyer (IDIBAPS), Hospital Clinic, University of Barcelona, Barcelona, Spain

u Virgen de la Victoria Hospital, Department of Endocrinology, Instituto de Investigación Biomédica de Málaga (IBIMA). University of Málaga, Málaga, Spain

${ }^{\vee}$ Department of Family Medicine, Research Unit, Distrito Sanitario Atención Primaria Sevilla, Sevilla, Spain

${ }^{\mathrm{w}}$ Research Institute of Biomedical and Health Sciences (IUIBS), University of Las Palmas de Gran Canaria \& Centro Hospitalario Universitario Insular Materno Infantil (CHUIMI), Canarian Health Service, Las Palmas de Gran Canaria, Spain

${ }^{x}$ Department of Preventive Medicine and Public Health, University of Granada, Granada, Spain

\footnotetext{
* Corresponding author. St. Michael's Hospital \#6138-61 Queen Street East, Toronto, ON, M5C 2T2, Canada.

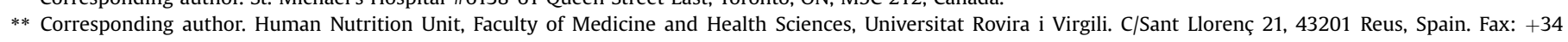
977759322.

E-mail addresses: john.sievenpiper@utoronto.ca (J.L. Sievenpiper), jordi.salas@urv.cat (J. Salas-alvadó).
} 
${ }^{\mathrm{y}}$ Research Group on Community Nutrition \& Oxidative Stress, University of Balearic Islands-IUNICS \& IDISBA, Palma de Mallorca, Spain

${ }^{\mathrm{z}}$ Institute of Biomedicine (IBIOMED), University of León, León, Spain

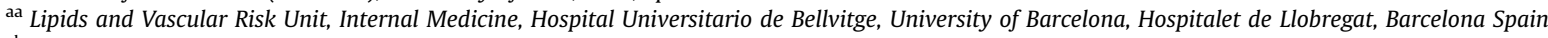

ab Division of Preventive Medicine, Faculty of Medicine, University of Jaén, Jaén, Spain

${ }^{\text {ac }}$ Department of Endocrinology and Nutrition, Instituto de Investigación Sanitaria Hospital Clínico San Carlos (IdISSC), Madrid, Spain

${ }^{\text {ad }}$ CIBER Diabetes y Enfermedades Metabólicas (CIBERDEM), Instituto de Salud Carlos III (ISCIII), Madrid, Spain

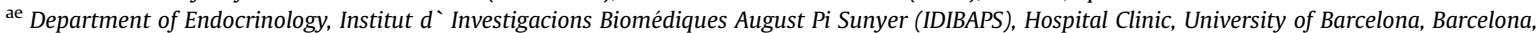
Spain

af Department of Endocrinology and Nutrition, Hospital Fundación Jimenez Díaz. Instituto de Investigaciones Biomédicas IISFJD. University Autonoma, Madrid, Spain

ag Lipid Clinic, Department of Endocrinology and Nutrition, Institut d'Investigacions Biomèdiques August Pi Sunyer (IDIBAPS), Hospital Clínic, Barcelona, Spain

ah Servicio Navarro de Salud, Pamplona, Spain

ai Li Ka Shing Knowledge Institute, St. Michael's Hospital, Toronto, Ontario, Canada

aj Department of Medicine, Temerty Faculty of Medicine, University of Toronto, Toronto, Ontario, Canada

\section{A R T I C L E I N F O}

\section{Article history:}

Received 2 November 2020

Accepted 12 March 2021

\section{Keywords:}

PORTFOLIO diet

DASH diet

Cardiometabolic risk

Dietary patterns

Metabolic syndrome

PREDIMED-Plus trial

\section{S U M M A R Y}

Background \& aims: The Portfolio and Dietary Approaches to Stop Hypertension (DASH) diets have been shown to lower cardiometabolic risk factors in randomized controlled trials (RCTs). However, the Portfolio diet has only been assessed in RCTs of hyperlipidemic patients. Therefore, to assess the Portfolio diet in a population with metabolic syndrome (MetS), we conducted a longitudinal analysis of one-year data of changes in the Portfolio and DASH diet scores and their association with cardiometabolic risk factors in Prevención con Dieta Mediterránea (PREDIMED)-Plus trial.

Methods: PREDIMED-Plus is an ongoing clinical trial (Trial registration: ISRCTN89898) conducted in Spain that includes 6874 older participants (mean age $65 \mathrm{y}, 48 \%$ women) with overweight/obesity fulfilling at least three criteria for MetS. Data for this analysis were collected at baseline, six months and one year. Adherence to the Portfolio and DASH diet scores were derived from a validated 143-item food frequency questionnaire. We used linear mixed models to examine the associations of 1-SD increase and quartile changes in the diet scores with concomitant changes in cardiometabolic risk factors.

Results: After adjusting for several potential confounders, a 1-SD increase in the Portfolio diet score was significantly associated with lower $\operatorname{HbA} 1 \mathrm{c}(\beta[95 \% \mathrm{CI}]:-0.02 \%[-0.02,-0.01], P<0.001)$, fasting glucose $(-0.47 \mathrm{mg} / \mathrm{dL}[-0.83,-0.11], P=0.01)$, triglycerides $(-1.29 \mathrm{mg} / \mathrm{dL}[-2.31,-0.28], P=0.01)$, waist circumference (WC) $(-0.51 \mathrm{~cm}[-0.59,-0.43], P<0.001)$, and body mass index $(\mathrm{BMI})\left(-0.17 \mathrm{~kg} / \mathrm{m}^{2}\right.$ $[-0.19,-0.15], P<0.001)$. A 1-SD increase in the DASH diet score was significantly associated with lower HbA1c $(-0.03 \%[-0.04,-0.02], P<0.001)$, glucose $(-0.84 \mathrm{mg} / \mathrm{dL}[-1.18,-0.51], P<0.001)$, triglycerides $(-3.38 \mathrm{mg} / \mathrm{dL}[-4.37,-2.38], P<0.001)$, non-HDL-cholesterol $(-0.47 \mathrm{mg} / \mathrm{dL}[-0.91,-0.04], P=0.03)$, WC $(-0.69 \mathrm{~cm}[-0.76,-0.60 \mathrm{~cm}], P<0.001)$, BMI $\left(-0.25 \mathrm{~kg} / \mathrm{m}^{2}\left[-0.28,-0.26 \mathrm{~kg} / \mathrm{m}^{2}\right], P<0.001\right)$, systolic blood pressure $(-0.57 \mathrm{mmHg}[-0.81,-0.32 \mathrm{mmHg}], P<0.001)$, diastolic blood pressure $(-0.15 \mathrm{mmHg}$ [-0.29, $-0.01 \mathrm{mmHg}], P=0.03)$, and with higher HDL-cholesterol $(0.21 \mathrm{mg} / \mathrm{dL}[0.09,0.34 \mathrm{mg} / \mathrm{dL}$, $P=0.001])$. Similar associations were seen when both diet scores were assessed as quartiles, comparing extreme categories of adherence.

Conclusions: Among older adults at high cardiovascular risk with MetS, greater adherence to the Portfolio and DASH diets showed significant favourable prospective associations with several clinically relevant cardiometabolic risk factors. Both diets are likely beneficial for cardiometabolic risk reduction.

(C) 2021 Elsevier Ltd and European Society for Clinical Nutrition and Metabolism. All rights reserved.

\section{Introduction}

Metabolic syndrome (MetS) is a cluster of cardiometabolic risk factors that continues to be a serious unmet health challenge [1]. Individuals with MetS are at an increased risk of multiple chronic diseases, including cardiovascular disease (CVD) and type 2 diabetes [2,3], which are leading causes of death worldwide [4,5]. Targeting the cardiometabolic risk factors characteristic of MetS (including dyslipidemia, high blood pressure and abnormal glucose control) can help decrease the burden of CVD and diabetes [6-9].

Two dietary patterns that were designed to target specific CVD risk factors include the Portfolio (or Dietary Portfolio) and the Dietary Approaches to Stop Hypertension (DASH) diets, both of which are recommended by international diabetes and CVD clinical practice guidelines [10-15]. The Portfolio diet is a plant-based dietary pattern that was originally developed to lower low-density lipoprotein cholesterol (LDL-C) [16-21]. The diet limits saturated fat and cholesterol (National Cholesterol Education Program (NCEP) Step II diet [22]), and includes a "portfolio" of 4 cholesterollowering foods and nutrients: nuts, plant protein, foods rich in viscous fiber, and phytosterols. An extension of the diet includes adding monounsaturated fats (MUFAs) in the form of olive/canola/ soy oil, or avocado [21]. In the randomized controlled trials (RCTs), the Portfolio diet has been shown to significantly reduce LDL-C by $27 \%$ (in the intended combination with a NCEP Step II diet), as well as significantly reduce the alternate blood lipid targets non-highdensity lipoprotein cholesterol (non-HDL-C) by $14 \%$, apolipoprotein B (apoB) by $15 \%$, and C-reactive protein by $32 \%$ [23]. On the other hand, the DASH diet was originally developed to treat high blood pressure and indeed resulted in clinically meaningful 
reductions in blood pressure [24]. The DASH diet emphasizes the consumption of fruit, vegetables, low-fat dairy, whole grains, nuts and legumes, and limits red and processed meats, sugary foods and sodium. In RCTs, the DASH diet also significantly reduced cardiometabolic risk factors beyond blood pressure, including LDL-C, glycated hemoglobin (HbA1c) and body weight compared to usual or low-fat diets [25].

After the DASH diet trials were conducted, several DASH diet scores were created to assess if the beneficial effects found in the RCTs translated into less disease outcomes in observational studies of diverse populations [26-29]. However, the Portfolio diet has not yet been assessed in populations outside the hyperlipidemic patients evaluated in the RCTs. Therefore, we have created a Portfolio diet score to assess associations with health outcomes in epidemiological study designs and in other populations. To ascertain whether the findings from RCTs translates to different populations, we examined the associations of one-year changes in the Portfolio and DASH diet scores with cardiometabolic risk factors in a large cohort of older adults with MetS.

\section{Materials \& methods}

\subsection{Study design}

This one-year longitudinal analysis was conducted within the framework of the Prevención con Dieta Mediterránea (PREDIMED)Plus trial. PREDIMED-Plus is an ongoing, six-year, multicenter, parallel-group randomized controlled trial conducted in Spain. The trial is evaluating the long-term effects of an energy-reduced Mediterranean diet with enhanced physical activity, behavioural support and weight loss (intervention) compared to an energyunrestricted Mediterranean diet (control) on the primary prevention of CVD. The overall design, methods and baseline characteristics of PREDIMED-Plus have been reported previously [30,31], and the protocol is available online at http://predimedplus.com. Ethics approval was obtained from the institutional review boards of all recruiting centers and all participants provided written informed consent before randomization. The data analyzed for this analysis was obtained from the PREDIMED-plus database of March 12th, 2019. The trial is registered at ISRCTN89898870.

\subsection{Participants}

Participants include older men (aged 55-75 years) and women (aged 60-75 years) with a body mass index (BMI) between 27 and $40 \mathrm{~kg} / \mathrm{m}^{2}$ and who fulfilled at least three criteria of the MetS [1]. Approximately $29 \%$ also had type 2 diabetes. All participants were free from CVD at enrollment. Further details of the inclusion and exclusion criteria can be found elsewhere [30,31]. Between 2013 and 2016, 6874 participants were recruited from the 23 participating centers in Spain. Participants were randomized in a 1:1 ratio to either the intervention or control group using a computer-generated random number internet-based system. For the present analysis, we excluded participants with implausible energy intake $(<500$ or $>3500 \mathrm{kcal} / \mathrm{d}$ for women and $<800$ or $>4000 \mathrm{kcal} / \mathrm{d}$ for men) or with missing information on the food frequency questionnaire (FFQ) at baseline. There were 6633 participants after baseline exclusions for all outcomes, except for HbA1c, which was available in 6091 participants.

\subsection{Dietary assessment}

Dietary data was collected at baseline, six months and one year using a previously validated 143 -item semi-quantitative FFQ [32-34]. Trained dietitians administered the FFQ and the energy and food nutrient content were calculated according to the Spanish
Food Tables [35,36]. Participants reported how often, on average, they consumed defined portions of the food items over the previous year through 9 response categories ranging from "never or almost never" to " $\geq 6$ times per day".

\subsection{Portfolio and DASH diet scores}

For the dietary pattern analyses, we used a previously created diet score for the DASH diet [26], and created a score for the Portfolio diet. The DASH diet score includes eight components: fruits, vegetables, whole grains, nuts and legumes, low-fat dairy, sodium (estimated from all foods), red and processed meats and sugar-sweetened beverages. Intake of each food component was ranked into sex-specific quintiles and given positive or reverse points. Positive points were given for foods recommended in the diet (fruits, vegetables, whole grains, nuts and legumes, and low-fat dairy), in which participants in the highest quintile of a food component received five points, and those in the lowest quintile received one point. Reverse points were given for foods or nutrients not recommended in the diet (sodium, red and processed meats, and sugar-sweetened beverages), in which participants in the highest quintile of a food component received one point, and those in the lowest quintile received five points. All food components were counted in servings/d, except for sodium intake $(\mathrm{mg} / \mathrm{d})$.

To create the Portfolio diet score, we followed the sex-specific quintile approach from the DASH diet score and gave positive points to food or nutrient components recommended in the diet (plant protein (legumes), nuts (all types), viscous fiber sources (berries, citrus fruit, eggplant, oats), phytosterols (estimated from all plant foods), and MUFAs from plant sources (olive and soy oils)) and reverse points for foods/nutrients not recommended in the diet (high saturated fat and cholesterol sources, including red and processed meats, high fat dairy and butter). All food components were in servings/d, except phytosterol intake $(\mathrm{mg} / \mathrm{d})$. The eight individual food/nutrient scores were summed for the DASH diet (score range of 8-40) and the six individual food/nutrient scores were summed for the Portfolio diet (score range of 6-30).

\subsection{Assessment of outcomes}

All outcomes were determined at baseline, six months and one year. Trained personnel measured anthropometric variables according to the PREDIMED-Plus protocol. Weight and height were measured with electronic calibrated scales and a wall-mounted stadiometer, respectively. BMI was calculated by dividing the weight $(\mathrm{kg})$ by the height squared $\left(\mathrm{m}^{2}\right)$. Waist circumference (WC) was measured halfway between the last rib and the iliac crest by using an anthropometric tape. BMI and WC were measured in duplicate. Blood pressure was measured in triplicate using a validated semiautomatic oscillometer (Omron HEM-705CP, Netherlands) after $5 \mathrm{~min}$ of rest in a seated position.

Blood samples were collected after an overnight fast and biochemical analyses were performed on fasting plasma glucose (FPG), total cholesterol (TC), high-density lipoprotein cholesterol (HDL-C), triglycerides (TG) and HbA1c. LDL-C was calculated using the Friedewald equation [37]. Non-HDL-C was calculated using the equation from the NCEP Expert Panel on Detection, Evaluation, and Treatment of High Blood Cholesterol in Adults (Adult Treatment Panel III) [38].

\subsection{Assessment of covariates}

Questionnaires were administered to participants at baseline, six months and one year to assess information on demographics, disease diagnoses, medication use and lifestyle factors such as 
physical activity and smoking. Physical activity was measured using the validated Minnesota-REGICOR Short Physical Activity questionnaire [39]. Participants were considered to have diabetes if they had a previous clinical diagnosis of the condition, had an $\mathrm{HbA} 1 \mathrm{c} \geq 6.5 \%$, used antidiabetic medication or insulin at baseline, or had a FPG $>126 \mathrm{mg} / \mathrm{dL}$ in both the screening visit and the baseline visit [40]. Hypertension was defined when systolic blood pressure (SBP) was $\geq 130 \mathrm{mmHg}$ and/or diastolic blood pressure (DBP) was $\geq 85 \mathrm{mmHg}$, or anti-hypertensive medication was used. Participants were considered to have hypercholesterolemia if their LDL-C was $\geq 130 \mathrm{mg} / \mathrm{dL}$ or if they were taking lipid-lowering medications.

\subsection{Statistical analyses}

Descriptive analysis by quartile of each diet score was conducted by using the chi-square test for categorical variables and ANOVA for continuous variables. We used linear mixed models with a random intercept for each participant and random slope for each visit (categorized as baseline, six months and one year) with an unstructured correlation matrix to examine the associations of changes in intake of the dietary indices with concomitant changes in cardiometabolic outcomes. In all models, we used robust variance estimators to account for intra-cluster correlations ( $n=402$ couples) to account for members of the same household who were randomized together. Cardiometabolic outcomes were truncated at the 1st and 99th percentiles to minimize the influence of outliers. Assumptions of normality were met for all outcomes, except TG, FGP and HbA1c. These three variables were log-transformed.

In each model, we adjusted for the following fixed covariates: sex (male/female), age (continuous), diabetes status (yes/no), intervention group (control/intervention), education (primary/ secondary/university), family history of CVD (yes/no), family history of diabetes (yes/no), center (categorized in quartiles by number of participants), hypertension status (yes/no), and hypercholesterolemia status (yes/no), and time-varying covariates: energy intake (continuous), smoking (never/former/current), physical activity (continuous), alcohol intake (continuous), statin therapy (yes/no), diabetes medications (yes/no), fibrate medications (yes/no), and anti-hypertensive medications (yes/no). The Portfolio diet analysis was additionally adjusted for time-varying sodium intake (continuous) for the blood pressure outcomes. We examined associations with the cardiometabolic outcomes with quartiles of change in each score and per-1 SD increase in each score to facilitate comparisons across the scores, as the Portfolio and DASH indices have different score ranges. Tests for linear trend were also conducted by assigning the median value to each quartile. We examined potential interactions with sex, BMI, diabetes status and intervention group. All models are presented as crude (unadjusted) and fully adjusted. All analyses were performed with STATA version 15.0 (StataCorp, College Station, TX, USA). Statistical significance was set at $P$ value $<0.05$.

\section{Results}

The participants' baseline characteristics are shown in Table 1. Those with better adherence to both the Portfolio and DASH diet scores were more likely to be older, have a lower BMI, be more physically active, have more education, and drink less alcohol, and were less likely to smoke, among others (Table 1). Those with better adherence to the DASH diet score were also more likely to be female (Table 1). The mean score and intake of the Portfolio diet score components in quintile 1 and 5 at each study visit are shown in Supplemental Table 1. The mean score and intake of the DASH diet score components in quintile 1 and 5 at each study visit are shown in Supplemental Table 2. The average Portfolio diet score did not change from baseline to six months ( $\beta$ coefficients $=-0.05$ (95\% CIs: $-0.16,0.07) \mathrm{P}=0.45$ ), and significantly increased from baseline to one year of intervention $(0.12(0.00,0.25), P=0.047)$. The average DASH diet score also did not change from baseline to six months $(0.12(-0.01,0.26), \mathrm{P}=0.08)$; however, the score did significantly increase from baseline to one year $(0.21(0.06,0.36)$, $\mathrm{P}=0.006)$, with greater changes observed in the DASH score. A higher percentage of participants, while small, also increased their DASH diet score over the one year compared to the Portfolio diet score (Supplemental Table 3).

As the scoring systems for the Portfolio and DASH diet scores are not based on absolute intakes from the RCTs, we estimated the absolute mean intakes in each quintile at baseline and one year in Supplemental Tables 4 and 5. Intake of plant protein, viscous fibre and phytosterols did not meet the recommendations of the Portfolio diet RCTs, even in the top quintiles, however, intake of nuts, MUFAs and saturated fat and cholesterol did meet recommendations from the RCTs in specific quintiles at both baseline and at one year (Supplemental Table 4). For the DASH diet score, RCT recommendations for most components (fruit, vegetables, nuts \& beans, low fat dairy, sodium, red \& processed meats and SSBs) were met in specific quintiles, and these recommendations were met in more quintiles at one year compared to baseline. Whole grain intake is the only component that may be improved in the PREDIMED-plus trial participants to further meet DASH diet recommendations (Supplemental Table 5). Overall, the PREDIMED-Plus participants were more closely meeting DASH diet recommendations compared to the Portfolio diet recommendations.

After adjusting for multiple potential confounders, each 1-SD increase in the Portfolio and DASH diet scores were not associated with either TC or LDL-C (Tables 2 and 3). Each 1-SD increase in the Portfolio diet score was associated with a decrease in TG. This inverse association was substantially stronger for the DASH diet score (Tables 2 and 3). Each 1-SD increase in the Portfolio diet score was not associated with increased HDL-C, however, each 1-SD increase in the DASH diet score was associated with increased HDL-C. Each 1-SD increase in the DASH diet score was also associated with lower non-HDL-C, but this was not significant for the Portfolio diet score (Tables 2 and 3 ).

When we adjusted for multiple potential confounders, each 1SD increases in the Portfolio and DASH diet scores were associated with a decrease in HbA1c (Tables 2 and 3). Similar inverse associations were seen with FPG. Each 1-SD increase in the Portfolio diet score was not associated with either SBP or DBP. Conversely, each 1-SD increase in the DASH diet score was associated with both lower SBP and DBP (Tables 2 and 3).

Each 1-SD increases in the Portfolio diet and DASH diet scores over the year were both associated with a lower BMI and WC (Tables 2 and 3 ), after adjusting for multiple potential confounders. We found similar results when we examined each of the cardiometabolic outcomes comparing extreme quartiles of diet score changes (Tables 2 and 3). A summary of the results per 1-SD increase of the Portfolio and DASH diet scores are shown in Figs. 1 and 2.

For the subgroup analyses (Supplemental Tables 6-16), the associations of the Portfolio diet score with higher HDL-C (Females: 0.23 (0.03, 0.43) mg/dL; Males: $-0.01(-0.19,0.17) \mathrm{mg} / \mathrm{dL}$, $\left.P_{\text {interaction }}=0.002\right)$ and lower TG (Females: $-2.70(-4.07,-1.35)$ $\mathrm{mg} / \mathrm{dL}$, Males: $\left.0.02(-1.45,1.50) \mathrm{mg} / \mathrm{dL}, P_{\text {interaction }}=0.01\right)$ were significant in females only (Supplemental Tables 8 and 9). The association of the DASH diet score with lower HbA1c (Diabetes: -0.06 $(-0.09,-0.03) \%$; No diabetes: $-0.02(-0.02,-0.01)$, Pinteraction $<0.001)$ was stronger in participants with diabetes, and associations with lower FPG were stronger in males and those with diabetes (Females: $-0.49(-0.96,-0.02) \mathrm{mg} / \mathrm{dL}$; Males: -1.09 
Table 1

Baseline characteristics of the 6636 PREDIMED-Plus participants according to quartiles of the Portfolio and DASH diet scores.

\begin{tabular}{|c|c|c|c|c|c|c|c|c|}
\hline \multirow[t]{2}{*}{ Mean (SD)/No. (\%) Range } & \multicolumn{4}{|c|}{ Portfolio Diet Score } & \multicolumn{4}{|c|}{ DASH Diet Score } \\
\hline & Q1 (6-14) & Q2 (15-17) & Q3 (18-20) & Q4 (21-30) & Q1 (8-21) & Q2 (22-24) & Q3 (25-27) & Q4 (28-39) \\
\hline $\mathrm{n}$ & 1864 & 1721 & 1602 & 1446 & 2026 & 1545 & 1426 & 1636 \\
\hline Median score & 12 & 16 & 19 & 22 & 19 & 23 & 26 & 30 \\
\hline Age, $y$ & $64.4(4.9)$ & $64.8(4.9)$ & $65.2(4.9)$ & $65.7(4.8)^{\mathrm{a}}$ & $64.2(4.9)$ & $65.0(5.0)$ & $65.2(4.9)$ & $65.8(4.8)^{\mathrm{a}}$ \\
\hline Sex, female & $933(50)$ & $827(48)$ & $764(48)$ & $685(47)$ & $921(45)$ & $712(46)$ & $737(52)$ & $839(51)^{a}$ \\
\hline European descent & $1799(97)$ & $1682(98)$ & $1574(98)$ & $1417(98)$ & $1973(97)$ & $1511(98)$ & $1397(98)$ & $1591(97)$ \\
\hline \multicolumn{9}{|l|}{ Current smoker } \\
\hline Never & $777(42)$ & $779(45)$ & $728(45)$ & $658(46)^{\mathrm{a}}$ & $825(41)$ & $683(44)$ & $653(46)$ & $781(48)^{a}$ \\
\hline Former & $805(43)$ & $741(43)$ & $697(44)$ & $627(43)^{\mathrm{a}}$ & $892(44)$ & $668(43)$ & $625(44)$ & $685(42)^{\mathrm{a}}$ \\
\hline Current & $282(15)$ & $201(12)$ & $177(11)$ & $161(11)^{\mathrm{a}}$ & $309(15)$ & $194(13)$ & $148(10)$ & $170(10)^{\mathrm{a}}$ \\
\hline BMI, $\mathrm{kg} / \mathrm{m}^{2}$ & $32.8(3.4)$ & $32.6(3.5)$ & $32.4(3.5)$ & $32.1(3.3)^{\mathrm{a}}$ & $32.8(3.5)$ & $32.6(3.4)$ & $32.5(3.4)$ & $32.1(3.4)^{\mathrm{a}}$ \\
\hline Allocated to intervention group & $910(49)$ & $872(51)$ & $782(49)$ & $731(51)$ & $1005(50)$ & $762(49)$ & $722(51)$ & $806(49)$ \\
\hline Exercise level, METs/min-week & $2196(2151)$ & $2401(2310)$ & $2546(2257)$ & $2793^{\mathrm{a}}(2478)$ & $2193(2154)$ & $2342(2212)$ & $2528(2365)$ & $2856^{\mathrm{a}}(2444)$ \\
\hline Family history of CVD & $767(41)$ & $714(42)$ & $623(39)$ & $593(41)$ & $805(40)$ & $616(40)$ & $594(42)$ & $682(42)$ \\
\hline Family history of diabetes & $791(42)$ & $715(42)$ & $651(41)$ & $594(41)$ & $836(41)$ & $622(40)$ & $613(43)$ & $680(42)$ \\
\hline \multicolumn{9}{|l|}{ Highest education attained } \\
\hline Primary school or less & $881(47)$ & $828(48)$ & $818(51)$ & $743(52)^{\mathrm{a}}$ & $936(46)$ & $776(50)$ & $727(51)$ & $831(51)^{\mathrm{a}}$ \\
\hline Complete secondary & $558(30)$ & $533(31)$ & $443(28)$ & $379(26)^{\mathrm{a}}$ & $645(32)$ & $426(28)$ & $420(29)$ & $422(26)^{\mathrm{a}}$ \\
\hline University & $425(23)$ & $360(21)$ & $341(21)$ & $324(24)^{a}$ & $445(22)$ & $343(22)$ & $279(20)$ & $383(23)^{a}$ \\
\hline Hypertension & $1730(93)$ & $1619(94)$ & $1506(94)$ & $1356(94)$ & $1894(93)$ & $1447(94)$ & $1344(94)$ & $1526(93)$ \\
\hline Hypercholesteremia & $1400(75)$ & $1334(78)$ & $1221(76)$ & $1079(75)$ & $1536(76)$ & $1163(75)$ & $1070(75)$ & $1265(77)$ \\
\hline Diabetes & $576(31)$ & $537(31)$ & $473(30)$ & $456(32)$ & $584(29)$ & $499(32)$ & $463(32)$ & $496(30)$ \\
\hline Statin therapy & $943(51)$ & $897(52)$ & $821(51)$ & $746(52)$ & $1036(51)$ & $782(51)$ & $714(50)$ & $875(53)$ \\
\hline Fibrates & $69(4)$ & $65(4)$ & $57(4)$ & $52(4)$ & $74(4)$ & $70(5)$ & $41(3)$ & $58(4)$ \\
\hline Antihypertensive agents & $1413(76)$ & $1349(78)$ & $1264(79)$ & $1127(78)$ & $1539(76)$ & $1219(79)$ & $1103(77)$ & $1292(79)$ \\
\hline Antidiabetic medications & $496(27)$ & $480(28)$ & $416(26)$ & $400(28)$ & $499(25)$ & $432(28)$ & $412(28)$ & $449(27)^{a}$ \\
\hline Total energy intake, kcal/d & $2098(530)$ & 2297 (509) & $2484(531)$ & $2657(464)^{\mathrm{a}}$ & $2461(572)$ & $2341(562)$ & $2318(533)$ & $2309(514)^{\mathrm{a}}$ \\
\hline Alcohol intake, g/d & $11.7(16.1)$ & $11.1(14.8)$ & $11.3(15.4)$ & $9.8(13.3)^{\mathrm{a}}$ & $14.1(17.4)$ & $11.6(15.2)$ & $9.4(13.5)$ & $8.2(12.0)^{\mathrm{a}}$ \\
\hline
\end{tabular}

Data is shown as mean (SD) or $\mathrm{N}(\%)$, unless otherwise stated.

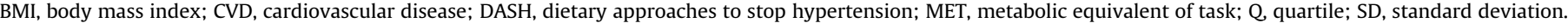

a Significantly different comparing Q1 to Q4.

$(-1.57,-0.62) \mathrm{mg} / \mathrm{dL}, \quad$ Pinteraction $=0.02$; Diabetes: -1.89 $(-2.89,-0.89) \mathrm{mg} / \mathrm{dL} ;$ No diabetes: $-0.49(-0.75,-0.24)$, Pinteraction $=0.002$ ) (Supplemental Tables 11 and 12). In addition, the association of the DASH diet score with lower SBP was significant only in participants in the active intervention group (Intervention: $-0.75(-1.09,-0.41) \mathrm{mmHg}$; Control: $-0.12(-0.46$, 0.22 ), $\left.P_{\text {interaction }}=0.01\right)$, and the association with lower BMI was stronger in males for the DASH diet score than in females (Females: $-0.22(-0.25,-0.18) \mathrm{kg} / \mathrm{m}^{2}$; Males: $-0.28(-0.31,-0.25)$ $\mathrm{kg} / \mathrm{m}^{2}, \mathrm{P}_{\text {interaction }}<0.001$ ) (Supplemental Tables 13 and 15). Lastly, the associations of both the Portfolio and DASH diet scores with lower DBP (Females: $0.33(0.12,0.54) \mathrm{mmHg}$; Males: $-0.09(-0.29$, $0.10) \mathrm{mmHg}, P_{\text {interaction }}=0.01$; Females: $0.04(-0.15,0.24) \mathrm{mmHg}$; Males: $-0.32(-0.50,-0.13) \mathrm{mmHg}, P_{\text {interaction }}=0.001$, for Portfolio and DASH diets, respectively) and WC (Females: $-0.08(-0.18,0.02)$ $\mathrm{cm}$; Males: $-0.18(-0.25,-0.10) \mathrm{cm}, \quad P_{\text {interaction }}=0.03$; Females: $-0.05(-0.15,0.06) \mathrm{cm}$; Males: $-0.24(-0.32,-0.16) \mathrm{cm}$, $\mathrm{P}_{\text {interaction }}<0.001$, for Portfolio and DASH diets, respectively) were significant or stronger in males only (Supplemental Tables 14 and 16).

\section{Discussion}

Our study analyzed the association of one-year changes in the Portfolio diet and DASH diet scores with changes in cardiometabolic risk factors in a large sample of older Spanish adults with overweight/obesity and MetS. We found that greater adherence to the Portfolio diet score was associated with lower TG, HbA1c, FPG, BMI and WC (Figs. 1 and 2). This is the first time that the Portfolio diet score has been related to improvements in markers of glycemic control and adiposity. We also found that greater adherence to the DASH diet score was associated with lower TG, non-HDL-C, HbA1c, FPG, SBP, DBP, BMI and WC (Figs. 1 and 2). The inverse association for TG was substantially stronger for the
DASH diet than the Portfolio diet. These findings indicate that both dietary patterns are likely beneficial for cardiometabolic disease reduction. The associations for the Portfolio diet and DASH diet scores were largely similar in the subgroup analyses in terms of direction and statistical significance, although the associations for various cardiometabolic risk factors were stronger in some subgroups (including sex, diabetes status, intervention group and BMI category). In addition, the associations of the Portfolio diet with higher HDL-C and lower TG were only significant in females. The differential findings in the subgroup analyses warrants further investigation.

\subsection{Context with previous literature}

To our knowledge, our study is the first to investigate associations between the Portfolio diet and cardiometabolic risk factors in a longitudinal cohort, therefore, comparison with existing literature outside of the Portfolio diet RCTs is difficult. When compared to the RCTs, both the findings in this study and the trials' results showed significant reductions/inverse associations with TG. However, we observed no inverse associations of the Portfolio diet score with TC, LDL-C or non-HDL-C in this study, which were lipid variables that were significantly reduced in the trials [23]. Furthermore, the RCTs did not assess markers of glycemic control and were not designed as weight loss studies, therefore, comparisons with FPG, HbA1c, BMI and WC are challenging. Nonetheless, we will await the results of the PortfolioEX trial (ClinicalTrials.gov Identifier: NCT02481466) of the effect of the Portfolio diet plus exercise on a surrogate marker of atherosclerotic CVD (magnetic resonance imaging of atherosclerosis (plaque volume)), in which some of the participants have type 2 diabetes and markers of glycemic control were measured. The discrepancies in results between our study and findings in the RCTs are possibly due to less change in the Portfolio Diet score over the one year compared to the DASH diet score, 
Table 2

Cardiometabolic changes over one-year according to 1-SD increase and quartiles of change in the Portfolio diet score.

\begin{tabular}{|c|c|c|c|c|c|c|c|}
\hline & Q1 & Q2 & Q3 & Q4 & P-trend ${ }^{a}$ & Per 1-SD increase & P-value ${ }^{b}$ \\
\hline \multicolumn{8}{|l|}{ Lipids } \\
\hline \multicolumn{8}{|l|}{$\mathrm{TC}(\mathrm{mg} / \mathrm{dL})$} \\
\hline Unadjusted model & 0 [reference] & $0.37(-0.69,1.43)$ & $0.47(-0.62,1.56)$ & $-0.33(-1.55,0.88)$ & 0.80 & $-0.12(-0.56,0.31)$ & 0.58 \\
\hline Multivariable model & 0 [reference] & $0.37(-0.67,1.41)$ & $0.16(-0.97,1.28)$ & $0.29(-1.02,1.59)$ & 0.71 & $0.48(-0.42,0.52)$ & 0.84 \\
\hline \multicolumn{8}{|l|}{ LDL-C (mg/dL) } \\
\hline Unadjusted model & 0 [reference] & $0.45(-0.47,1.37)$ & $0.64(-0.31,1.60)$ & $-0.07(-1.10,0.96)$ & 0.82 & $0.04(-0.32,0.42)$ & 0.82 \\
\hline Multivariable model & 0 [reference] & $0.38(-0.52,1.27)$ & $0.19(-0.78,1.16)$ & $0.19(-0.90,1.27)$ & 0.75 & $0.08(-0.32,0.47)$ & 0.71 \\
\hline \multicolumn{8}{|l|}{ HDL-C (mg/dL) } \\
\hline Unadjusted model & 0 [reference] & $0.30(0.03,0.56)^{\mathrm{d}}$ & $0.37(0.09,0.66)^{\mathrm{d}}$ & $0.35(0.03,0.66)^{\mathrm{d}}$ & 0.02 & $0.12(0.01,0.24)$ & 0.04 \\
\hline Multivariable model & 0 [reference] & $0.25(-0.04,0.53)$ & $0.33(0.02,0.64)^{\mathrm{d}}$ & $0.36(0.00,0.72)^{\mathrm{d}}$ & 0.03 & $0.16(-0.02,0.25)$ & 0.09 \\
\hline \multicolumn{8}{|l|}{$\mathbf{T G}(\mathbf{m g} / \mathbf{d L})^{\mathrm{c}}$} \\
\hline Unadjusted model & 0 [reference] & $-1.96(-4.02,0.05)$ & $-3.12(-5.23,-1.01)^{\mathrm{d}}$ & $-3.70(-6.07,-1.32)^{\mathrm{d}}$ & $<0.001$ & $-1.78(-2.62,-0.92)$ & $<0.001$ \\
\hline Multivariable model & 0 [reference] & $-1.63(-3.77,0.51)$ & $-2.16(-4.48,0.14)$ & $-2.37(-5.10,0.35)$ & 0.04 & $-1.29(-2.31,-0.28)$ & $<0.01$ \\
\hline \multicolumn{8}{|l|}{ Non-HDL-C (mg/dL) } \\
\hline Unadjusted model & 0 [reference] & $-0.03(-1.04,0.98)$ & $0.03(-1.01,1.07)$ & $-0.78(-1.93,0.37)$ & 0.23 & $-0.28(-0.69,0.13)$ & 0.18 \\
\hline Multivariable model & 0 [reference] & $0.01(-0.97,1.01)$ & $-0.20(-1.27,0.86)$ & $-0.15(-1.38,1.07)$ & 0.73 & $-0.10(-0.55,0.35)$ & 0.67 \\
\hline \multicolumn{8}{|c|}{ Markers of glycemic control } \\
\hline \multicolumn{8}{|l|}{ HbA1c (\%) ${ }^{c}$} \\
\hline Unadjusted model & 0 [reference] & $-0.01(-0.03,0.01)$ & $-0.01(-0.03,0.01)$ & $-0.02(-0.04,-0.00)^{\mathrm{d}}$ & 0.04 & $-0.01(-0.02,-0.00)$ & 0.02 \\
\hline Multivariable model & 0 [reference] & $-0.03(-0.05,-0.01)^{\mathrm{d}}$ & $-0.03(-0.05,-0.01)^{\mathrm{d}}$ & $-0.05(-0.07,-0.02)^{\mathrm{d}}$ & $<0.001$ & $-0.02(-0.03,-0.01)$ & $<0.001$ \\
\hline \multicolumn{8}{|l|}{ FPG $(\mathbf{m g} / \mathbf{d L})^{\mathrm{c}}$} \\
\hline Unadjusted model & 0 [reference] & $-0.50(-1.20,0.20)$ & $-0.20(-0.02,0.51)$ & $-0.94(1.78,-0.09)^{\mathrm{d}}$ & 0.01 & $-0.36(-0.66,-0.06)$ & $<0.01$ \\
\hline Multivariable model & 0 [reference] & $-0.97(-1.76,-0.18)^{\mathrm{d}}$ & $-0.41(-1.27,0.45)$ & $-1.32(-2.33,-0.30)^{\mathrm{d}}$ & 0.02 & $-0.47(-0.83,-0.11)$ & $<0.01$ \\
\hline \multicolumn{8}{|c|}{ Blood Pressure Measurements } \\
\hline \multicolumn{8}{|l|}{ SBP (mmHg) } \\
\hline Unadjusted model & 0 [reference] & $0.09(-0.41,0.59)$ & $0.07(-0.46,0.60)$ & $-0.03(-0.61,0.54)$ & 0.96 & $-0.02(-0.19,0.23)$ & 0.88 \\
\hline Multivariable model & 0 [reference] & $0.01(-0.52,0.54)$ & $0.02(-0.57,0.61)$ & $-0.14(-0.70,0.68)$ & 0.85 & $-0.01(-0.27,0.24)$ & 0.93 \\
\hline \multicolumn{8}{|l|}{ DBP (mmHg) } \\
\hline Unadjusted model & 0 [reference] & $-0.06(-0.35,0.22)$ & $-0.01(-0.30,0.29)$ & $-0.05(-0.38,0.27)$ & 0.83 & $0.004(-0.13,0.12)$ & 0.94 \\
\hline Multivariable model & 0 [reference] & $-0.04(-0.34,0.26)$ & $0.11(-0.22,0.43)$ & $0.17(-0.22,0.56)$ & 0.39 & $0.07(-0.06,0.23)$ & 0.24 \\
\hline \multicolumn{8}{|l|}{ Markers of obesity } \\
\hline \multicolumn{8}{|l|}{ BMI $\left(\mathrm{kg} / \mathrm{m}^{2}\right)$} \\
\hline Unadjusted model & 0 [reference] & $-0.09(-0.13,-0.05)^{\mathrm{d}}$ & $-0.14(-0.19,-0.09)^{\mathrm{d}}$ & $-0.23(-0.28,-0.17)^{\mathrm{d}}$ & $<0.001$ & $-0.09(-0.11,-0.07)$ & $<0.001$ \\
\hline Multivariable model & 0 [reference] & $-0.15(-0.20,-0.11)^{\mathrm{d}}$ & $-0.25(-0.30,-0.20)^{d}$ & $-0.41(-0.47,-0.35)^{\mathrm{d}}$ & $<0.001$ & $-0.17(-0.19,-0.15)$ & $<0.001$ \\
\hline \multicolumn{8}{|l|}{ WC $(\mathrm{cm})$} \\
\hline Unadjusted model & 0 [reference] & $-0.25(-0.41,-0.10)^{\mathrm{d}}$ & $-0.40(-0.57,-0.23)^{\mathrm{d}}$ & $-0.72(-0.91,-0.53)^{\mathrm{d}}$ & $<0.001$ & $-0.28(-0.35,-0.22)$ & $<0.001$ \\
\hline Multivariable model & 0 [reference] & $-0.46(-0.63,-0.30)^{\mathrm{d}}$ & $-0.72(-0.91,-0.54)^{\mathrm{d}}$ & $-1.26(-1.47,-1.04)^{\mathrm{d}}$ & $<0.001$ & $-0.51(-0.59,-0.43)$ & $<0.001$ \\
\hline
\end{tabular}

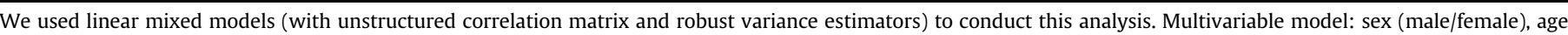

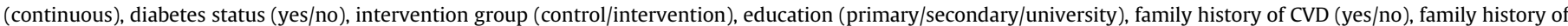

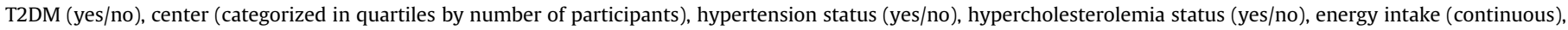

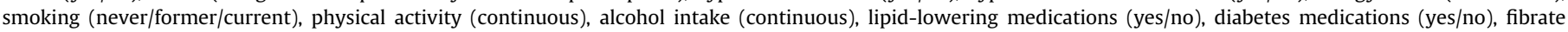

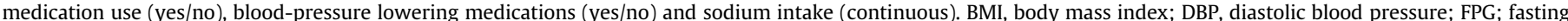

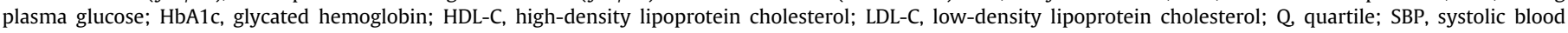
pressure; SD, standard deviation; TG, triglycerides; TC, total cholesterol; WC, waist circumference.

${ }^{a} P$ for trend obtained from assigning the median value to each quartile.

b $P$ value obtained from per $1-S D$ increase in $\beta$ coefficients.

c As results for both non and log transformed data were similar, the values of the non-transformed data were provided for ease of interpretation. The P-value provided is from the log transformed data analysis.

d Significantly different compared to Q1.

lower consumption of the foods recommended in the diet, the population being studied and missing foods on the FFQ in our study, as discussed below. However, the single components of the Portfolio diet (i.e. plant protein, nuts, viscous fiber sources, phytosterols and MUFAs) have shown favourable associations with cardiometabolic outcomes, such as TC and LDL-C [41,42], obesity [41,43], blood pressure and TG [43], in addition to associations with a lower risk of CVD and diabetes in prospective cohort studies [44-52].

For the DASH diet, both the findings in this study and those from prior RCTs suggest significant reductions/inverse associations with SBP, DBP, HbA1c and body weight; however, we observed significant associations with higher HDL-C, and lower TG and FPG in this study, which was not reported in the RCTs [25]. Still, the DASH diet has been extensively examined in prospective cohort studies, and favourable associations with cardiometabolic outcomes have been documented, including higher HDL-C and lower TG [53-55], and lower BP [55], as well as associations with lower incident CVD, diabetes, non-alcoholic fatty liver disease (NALFD), and total mortality [25,56,57].

In our study, greater adherence to the DASH diet was associated with more improvements of cardiometabolic outcomes than the Portfolio diet. The average DASH diet score increased slightly more over the one-year period compared to the Portfolio diet score, with most of this change in the Portfolio diet coming from small increases in nut consumption and reductions in foods high in saturated fat and cholesterol. The recommendations of the DASH diet may also more closely mimic those of the PREDIMED-Plus trial, as highlighted by the 17-point screener used to assess adherence in the main trial $[30,31,58]$. For example, in the PREDIMED-Plus trial, 
Table 3

Cardiometabolic changes over one-year according to 1-SD increase and quartiles of change in the DASH diet score.

\begin{tabular}{|c|c|c|c|c|c|c|c|}
\hline & Q1 & Q2 & Q3 & Q4 & P-trend ${ }^{\mathrm{a}}$ & Per 1-SD increase & P-value ${ }^{b}$ \\
\hline \multicolumn{8}{|l|}{ Lipids } \\
\hline \multicolumn{8}{|l|}{ TC (mg/dL) } \\
\hline Unadjusted model & 0 [reference] & $-1.07(-2.14,0.00)$ & $-1.08(-2.23,0.09)$ & $-1.75(-2.99,-0.51)^{\mathrm{d}}$ & 0.02 & $-0.53(-1.00,-0.06)$ & 0.03 \\
\hline Multivariable model & 0 [reference] & $-0.61(-1.67,0.44)$ & $-0.76(-1.90,0.39)$ & $-0.74(-1.96,0.49)$ & 0.34 & $-0.18(-0.64,0.28)$ & 0.45 \\
\hline \multicolumn{8}{|l|}{ LDL-C (mg/dL) } \\
\hline Unadjusted model & 0 [reference] & $-0.36(-1.29,0.57)$ & $-0.11(-1.11,0.88)$ & $-0.19(-1.26,0.88)$ & 0.90 & $0.07(-0.33,0.48)$ & 0.72 \\
\hline Multivariable model & 0 [reference] & $-0.05(-0.95,0.86)$ & $0.05(-0.92,1.02)$ & $0.24(-0.79,1.28)$ & 0.57 & $0.19(-0.20,0.58)$ & 0.34 \\
\hline \multicolumn{8}{|l|}{ HDL-C (mg/dL) } \\
\hline Unadjusted model & 0 [reference] & $0.35(0.07,0.62)^{\mathrm{d}}$ & $0.49(0.20,0.78)^{\mathrm{d}}$ & $0.74(0.42,1.07)^{\mathrm{d}}$ & $<0.001$ & $0.28(0.16,0.40)$ & $<0.001$ \\
\hline Multivariable model & 0 [reference] & $0.16(-0.13,0.45)$ & $0.30(-0.01,0.61)$ & $0.53(0.19,0.87)^{d}$ & $<0.01$ & $0.21(0.09,0.34)$ & 0.001 \\
\hline \multicolumn{8}{|l|}{ TG $(\mathbf{m g} / \mathbf{d L})^{\mathrm{c}}$} \\
\hline Unadjusted model & 0 [reference] & $-6.47(-8.62,-4.30)^{\mathrm{d}}$ & $-8.43(-10.7,-6.16)^{\mathrm{d}}$ & $-13.3(-15.7,-10.8)^{\mathrm{d}}$ & $<0.001$ & $-5.06(-5.98,-4.14)$ & $<0.001$ \\
\hline Multivariable model & 0 [reference] & $-4.57(-6.86,-2.27)^{\mathrm{d}}$ & $-6.64(-9.03,-4.25)^{\mathrm{d}}$ & $-8.83(-11.5,-6.19)^{\mathrm{d}}$ & $<0.001$ & $-3.38(-4.37,-2.38)$ & $<0.001$ \\
\hline \multicolumn{8}{|l|}{ Non-HDL-C (mg/dL) } \\
\hline Unadjusted model & 0 [reference] & $-1.49(-2.51,-0.47)^{\mathrm{d}}$ & $-1.65(-2.75,-0.55)^{\mathrm{d}}$ & $-2.60(-3.78,-1.42)^{\mathrm{d}}$ & $<0.001$ & $-0.86(-1.30,-0.41)$ & $<0.001$ \\
\hline Multivariable model & 0 [reference] & $-0.89(-1.90,0.11)$ & $-1.20(-2.29,-0.11)^{\mathrm{d}}$ & $-1.48(-2.65,-0.31)^{d}$ & 0.03 & $-0.47(-0.91,-0.04)$ & 0.03 \\
\hline \multicolumn{8}{|c|}{ Markers of glycemic control } \\
\hline \multicolumn{8}{|l|}{ HbA1c (\%) ${ }^{c}$} \\
\hline Unadjusted model & 0 [reference] & $-0.02(-0.04,-0.01)^{\mathrm{d}}$ & $-0.05(-0.07,-0.03)^{\mathrm{d}}$ & $-0.09(-0.12,-0.07)^{\mathrm{d}}$ & $<0.001$ & $-0.04(-0.05,-0.03)$ & $<0.001$ \\
\hline Multivariable model & 0 [reference] & $-0.02(-0.04,0.01)$ & $-0.03(-0.05,-0.01)^{\mathrm{d}}$ & $-0.07(-0.09,-0.04)^{\mathrm{d}}$ & $<0.001$ & $-0.03(-0.04,-0.02)$ & $<0.001$ \\
\hline \multicolumn{8}{|l|}{ FPG $(\mathbf{m g} / \mathbf{d L})^{\mathrm{c}}$} \\
\hline Unadjusted model & 0 [reference] & $-1.31(-2.02,-0.60)^{\mathrm{d}}$ & $-2.23(-2.99,-1.47)^{\mathrm{d}}$ & $-2.99(-3.82,-2.14)^{\mathrm{d}}$ & $<0.001$ & $-1.27(-1.58,-0.94)$ & $<0.001$ \\
\hline Multivariable model & 0 [reference] & $-0.86(-1.65,-0.05)^{\mathrm{d}}$ & $-1.61(-2.46,-0.76)^{\mathrm{d}}$ & $-2.14(-3.04,-1.24)^{d}$ & $<0.001$ & $-0.84(-1.18,-0.51)$ & $<0.001$ \\
\hline \multicolumn{8}{|c|}{ Blood Pressure Measurements } \\
\hline \multicolumn{8}{|l|}{$\overline{\text { SBP (mmHg) }}$} \\
\hline Unadjusted model & 0 [reference] & $-0.62(-1.13,-0.10)^{\mathrm{d}}$ & $-1.12(-1.77,-0.61)^{\mathrm{d}}$ & $-2.27(-2.89,-1.66)^{\mathrm{d}}$ & $<0.001$ & $-0.81(-1.04,-0.58)$ & $<0.001$ \\
\hline Multivariable model & 0 [reference] & $-0.42(-0.96,0.12)$ & $-0.70(-1.31,-0.10)^{\mathrm{d}}$ & $-1.61(-2.26,-0.98)^{\mathrm{d}}$ & $<0.001$ & $-0.57(-0.81,-0.32)$ & $<0.001$ \\
\hline \multicolumn{8}{|l|}{ DBP (mmHg) } \\
\hline Unadjusted model & 0 [reference] & $-0.28(-0.56,0.01)$ & $-0.64(-0.95,-0.32)^{\mathrm{d}}$ & $-1.17(-1.51,-0.84)^{\mathrm{d}}$ & $<0.001$ & $-0.47(-0.59,-0.34)$ & $<0.001$ \\
\hline Multivariable model & 0 [reference] & $-0.05(-0.35,0.24)$ & $-0.12(-0.45,0.20)$ & $-0.47(-0.82,-0.12)^{\mathrm{d}}$ & $<0.01$ & $-0.15(-0.29,-0.01)$ & 0.02 \\
\hline \multicolumn{8}{|l|}{ Markers of obesity } \\
\hline \multicolumn{8}{|l|}{ BMI $\left(\mathrm{kg} / \mathrm{m}^{2}\right)$} \\
\hline Unadjusted model & 0 [reference] & $-0.22(-0.26,-0.17)^{\mathrm{d}}$ & $-0.38(-0.43,-0.33)^{\mathrm{d}}$ & $-0.61(-0.67,-0.55)^{d}$ & $<0.001$ & $-0.27(-0.29,-0.25)$ & $<0.001$ \\
\hline Multivariable model & 0 [reference] & $-0.19(-0.23,-0.14)^{d}$ & $-0.35(-0.40,-0.29)^{\mathrm{d}}$ & $-0.57(-0.64,-0.52)^{\mathrm{d}}$ & $<0.001$ & $-0.25(-0.28,-0.23)$ & $<0.001$ \\
\hline \multicolumn{8}{|l|}{ WC $(\mathbf{c m})$} \\
\hline Unadjusted model & 0 [reference] & $-0.60(-0.76,-0.43)^{\mathrm{d}}$ & $-1.17(-1.35,-0.99)^{\mathrm{d}}$ & $-1.82(-2.03,-1.61)^{\mathrm{d}}$ & $<0.001$ & $-0.77(-0.85,-0.69)$ & $<0.001$ \\
\hline Multivariable model & 0 [reference] & $-0.45(-0.63,-0.28)^{\mathrm{d}}$ & $-1.00(-1.20,-0.81)^{\mathrm{d}}$ & $-1.64(-1.86,-1.43)^{d}$ & $<0.001$ & $-0.69(-0.76,-0.60)$ & $<0.001$ \\
\hline
\end{tabular}

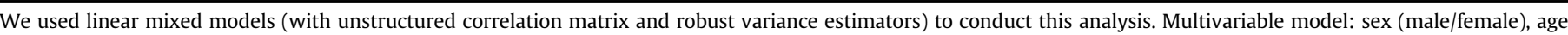

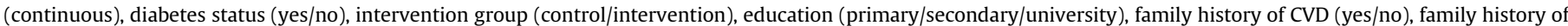

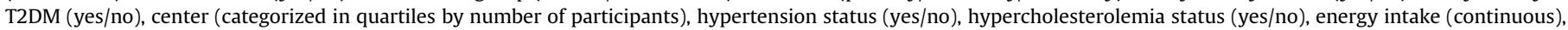

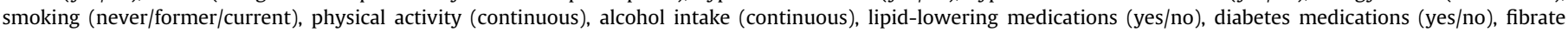

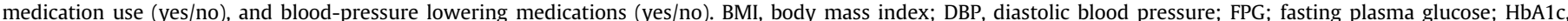

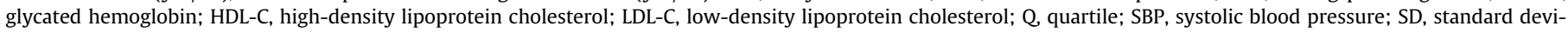
ation; TG, triglycerides; TC, total cholesterol; WC, waist circumference.

${ }^{a} P$ for trend obtained from assigning the median value to each quartile.

b $P$ value obtained from per $1-S D$ increase in $\beta$ coefficients.

c As results for both non and log transformed data were similar, the values of the non-transformed data were provided for ease of interpretation. The P-value provided is from the log transformed data analysis.

d Significantly different compared to Q1.

dietary advice is given to increase fruit, vegetable and whole grain consumption, and limit sugar-sweetened beverages. While some of these dietary recommendations are included in the Portfolio diet score, they more closely align with the DASH diet, and may explain why the DASH diet score increased more over time compared to the Portfolio diet score. When assessing estimates of absolute intake of the Portfolio and DASH diet recommendations in this study, we also observed that more PREDIMED-Plus participants met the DASH trial recommendations compared to the Portfolio diet recommendations. Both the Mediterranean diet and Portfolio Diet recommend higher nut and extra virgin olive oil consumption, and lower saturated fat consumption, however, the Portfolio diet has more focus on plant protein, high viscous fiber sources and phytosterols, and consumption of these three components was low in the PREDIMED-trial participants, indicating room for improvement.
This smaller change in the Portfolio diet score over the one-year may result in lack of associations with outcomes. For example, a recent study that assessed 10 -year longitudinal changes in plantbased diet indices and anthropometric parameters and blood lipids found that the plant-based diet indices did not change overtime, and as a result, few significant associations were observed with the anthropometrics and blood lipids [59]. The small increase in the Portfolio diet score over the study period may explain some of the lack of associations found with several risk factors compared to the DASH diet score in our study. Although in our study, the DASH diet score showed more favourable associations with the cardiometabolic outcomes, their direction was similar for both the DASH and Portfolio diet scores.

Another important consideration when evaluating our findings is the population being studied. All participants in the PREDIMED- 


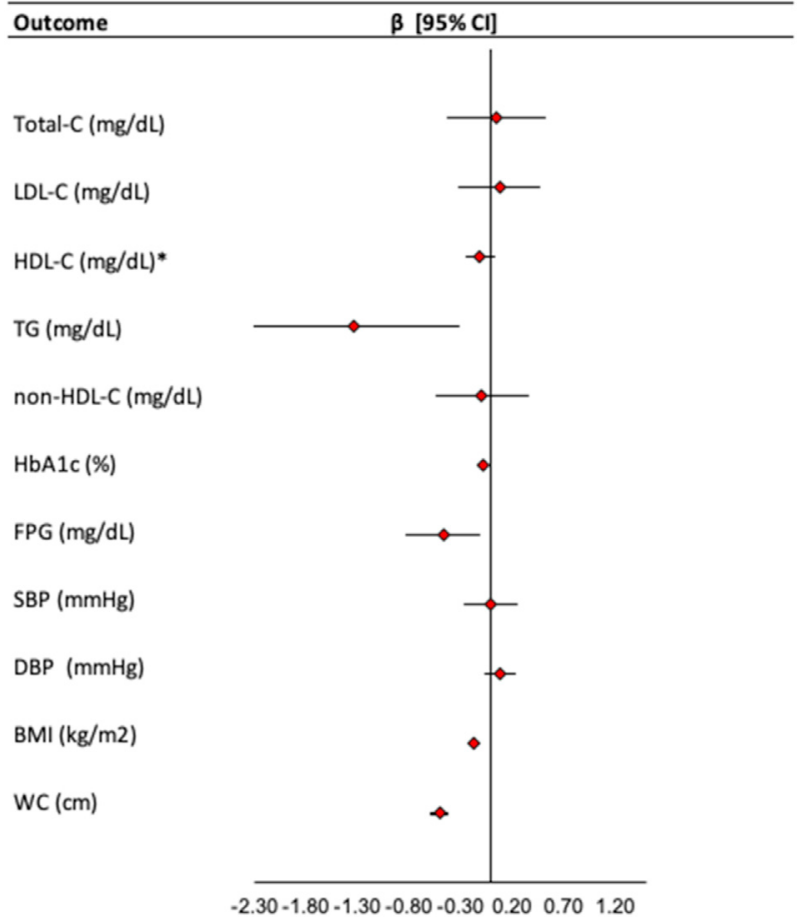

Fig. 1. Summary plot of the longitudinal association between 1- unit SD increase in Portfolio diet and cardiometabolic outcomes over 1-year in PREDIMED-plus. We used linear mixed models (with unstructured correlation matrix and robust variance estimators) to conduct this analysis. Multivariable model: sex (male/female), age (continuous), diabetes status (yes/no), intervention group (control/intervention), education (primary/secondary/university), family history of CVD (yes/no), family history of T2DM (yes/no), center (categorized in quartiles by number of participants), hypertension status (yes/no), hypercholesterolemia status (yes/no), energy intake (continuous), smoking (never/former/current), physical activity (continuous), alcohol intake (continuous), lipid-lowering medications (yes/no), diabetes medications (yes/no), fibrate medication use (yes/no), blood-pressure lowering medications (yes/no) and sodium intake (continuous). BMI, body mass index; DBP, diastolic blood pressure; FPG; fasting plasma glucose; HbA1c, glycated hemoglobin; HDL-C, high-density lipoprotein cholesterol; LDL-C, low-density lipoprotein cholesterol; Q quartile; SBP, systolic blood pressure; SD, standard deviation; TG, triglycerides; TC, total cholesterol; WC, waist circumference. Data are $\beta$-coefficients $(95 \% \mathrm{CIs})$. *The reciprocal of the actual $\beta$-coefficient for HDL-C was provided so that it could be presented on the same scale (benefit vs. harm) as the other outcomes.

Plus trial cohort are older adults with overweight/obesity and MetS. The dyslipidemia present in individuals with MetS is characterized by elevated TG, low levels of HDL-C, high apoB and small LDL particles [60]. High blood pressure, elevated glucose and overweight are also features of the MetS. These metabolic characteristics may explain why many of the associations that are typical of MetS improved with increasing adherence to the diet scores, whereas associations with other outcomes (including TC and LDLC) did not. The lipid abnormalities in MetS typically do not include elevated TC and LDL-C [60], therefore, there may be less room for improvement of these outcomes in our population. We did not assess small and dense LDL-C particles or apoB; however, non-HDL-C would capture these atherogenic lipoproteins. Greater adherence to the DASH diet score was only significantly associated with non-HDL-C in our study, but the direction of the association was similar for the Portfolio diet score.

The sex-specific differences findings are also noteworthy. We found that the Portfolio diet score was associated with higher HDL$\mathrm{C}$ and lower TG in females only. We also observed that the DASH diet score had stronger associations or was only significantly related with lower DBP and FPG in males. A stronger association with lower BMI and WC was also seen in males compared to

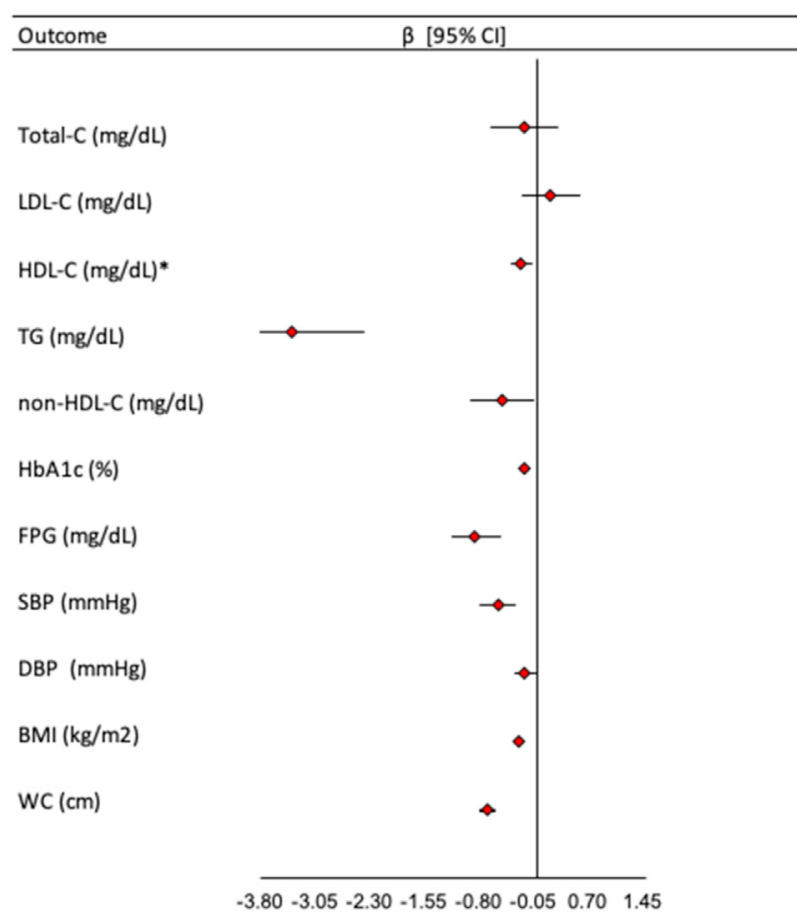

Fig. 2. Summary plot of the longitudinal association between 1- unit SD increase in DASH diet and cardiometabolic outcomes over 1-year in PREDIMED-plus. We used linear mixed models (with unstructured correlation matrix and robust variance estimators) to conduct this analysis. Multivariable model: sex (male/female), age (continuous), diabetes status (yes/no), intervention group (control/intervention), education (primary/secondary/university), family history of CVD (yes/no), family history of T2DM (yes/no), center (categorized in quartiles by number of participants), hypertension status (yes/no), hypercholesterolemia status (yes/no), energy intake (continuous), smoking (never/former/current), physical activity (continuous), alcohol intake (continuous), lipid-lowering medications (yes/no), diabetes medications (yes/no), fibrate medication use (yes/no), and blood-pressure lowering medications (yes/no). BMI, body mass index; DBP, diastolic blood pressure; FPG; fasting plasma glucose; HbA1c, glycated hemoglobin; HDL-C, high-density lipoprotein cholesterol; LDL-C, lowdensity lipoprotein cholesterol; Q quartile; SBP, systolic blood pressure; SD, standard deviation; TG, triglycerides; TC, total cholesterol; WC, waist circumference. Data are $\beta$ coefficients (95\% CIs). *The reciprocal of the actual $\beta$-coefficient for HDL-C was provided so that it could be presented on the same scale (benefit vs. harm) as the other outcomes.

females for both diet scores. While in the original Portfolio trials no effect differences by sex were reported [23], women had greater blood pressure reduction in a DASH diet trial compared to men [24], in which the opposite association was shown in our study, where significant associations with lower DBP was observed in males only. Other sex-differences have also been observed in nutrition research. For example, lower carbohydrate quality (higher glycemic index and load) have been associated with stronger risk of type 2 diabetes and CVD in females compared to males [61,62]. Interestingly, sex differences have also been found with the effects of a Mediterranean diet, with men having better responses to the diet $[63,64]$, similar to some of the findings in our study. This highlights the importance of investigating sex-related differences to diets, and warrants further investigation, particularly for the PREDIMED-Plus trial once complete.

Lastly, it is important to consider the clinical relevance of our findings. Based on minimally important differences we have used in previous systematic reviews and meta-analyses conducted by our group $[23,25,65,66]$, many of the effect sizes we saw for the cardiometabolic outcomes are small and may not be clinically relevant. However, the inverse associations found with both diet scores and TG and BMI are considered clinically relevant. Inverse 
associations seen with WC and SBP (for the DASH diet score) were also close to clinically relevant reductions $[23,25,65,66]$. Nevertheless, the beneficial associations found with the cardiometabolic risk factors, despite being small for some outcomes, may still be important as they may favourably impact cardiometabolic disease risk on a population level.

\subsection{Strengths and limitations}

Strengths of our study include the large sample size and longitudinal design that assessed changes in the diet scores and concomitant changes in cardiometabolic risk factors over one-year. Nevertheless, our study does have some limitations. First, the dietary intake was assessed via self-report. Second, the population included older Mediterranean adults with overweight/obesity and MetS, therefore, the results may not be extrapolated to other populations. Third, one of the key components of the Portfolio diet (i.e., soy foods) was not included in the PREDIMED-Plus FFQ due to limited consumption of these foods in Spain [33,67]. Future analyses in a population that consumes more soy foods would be needed. Despite adjusting our models for the intervention group, there still may be some bias in our analyses related to the trial intervention/Mediterranean diet that we cannot account for, although this is common to all longitudinal analyses using a clinical trial as a cohort. Some of the beneficial associations we found with the cardiometabolic risk factors were also not considered clinically relevant. Lastly, residual confounding cannot be discounted due to the observational nature of the study design, and therefore causal relations cannot be inferred.

\subsection{Conclusion}

In conclusion, greater adherence to both the Portfolio and DASH diet scores were associated with improvements in several cardiometabolic risk factors in patients with MetS. As this was the first time that the Portfolio diet score was assessed in a cohort with cardiometabolic risk factors, our findings need to be confirmed in other populations. Future studies should also evaluate the Portfolio diet score with incident CVD and diabetes to assess whether improved cardiometabolic risk observed in prior RCTs and in this study translates into lower clinical events. Overall, our results support existing literature that both dietary patterns may be a useful therapeutic nutrition strategy for preventing and managing CVD and type 2 diabetes.

\section{Statement of authorship}

MAM-G, DC, MF, DR, JV, AA-G, JW, JAM, LS-M, RE, FJT, JL, XP, JT, AB, MD-R, PM-M, LD, VMS, JV, CV, ER, JS-S collected the data for the PREDIMED-Plus Trial. AJG, DJAJ, CWCK, JLS and JS-S designed the study concept. AJG wrote the first draft of the manuscript. AJG and PH-A conducted the statistical analysis. JLS and JS-S supervised the study. All authors provided interpretation of the data and critical revision of the manuscript for intellectual content. All authors approved the final version of the manuscript.

\section{Funding sources}

The PREDIMED-Plus trial was supported by the Spanish government's official funding agency for biomedical research, ISCIII, through the Fondo de Investigación para la Salud (FIS) and cofunded by European Union ERDF/ESF, "A way to make Europe"/ "Investing in your future" (five coordinated FIS projects led by JS-S and JVid, including the following projects: PI13/00673, PI13/00492, PI13/00272, PI13/01123, PI13/00462, PI13/00233, PI13/02184, PI13/
00728, PI13/01090, PI13/01056, PI14/01722, PI14/00636, PI14/ 00618, PI14/00696, PI14/01206, PI14/01919, PI14/00853, PI14/ 01374, PI14/00972, PI14/00728, PI14/01471, PI16/00473, PI16/ 00662, PI16/01873, PI16/01094, PI16/00501, PI16/00533, PI16/ 00381, PI16/00366, PI16/01522, PI16/01120, PI17/00764, PI17/ 01183,PI17/00855, PI17/01347, PI17/00525, PI17/01827, PI17/00532, PI17/00215, PI17/01441, PI17/00508, PI17/01732, PI17/00926, PI19/ 00957, PI19/00386, PI19/00309, PI19/01032, PI19/00576, PI19/ 00017, PI19/01226, PI19/00781, PI19/01560, and PI19/01332), the Special Action Project entitled: Implementación y evaluación de una intervención intensiva sobre la actividad física Cohorte PREDIMED-Plus grant to JS-S, the European Research Council (Advanced Research Grant 2014-2019, 340918) to MÁM-G, the Recercaixa Grant to JS-S (2013ACUP00194), grants from the Consejería de Salud de la Junta de Andalucía (PI0458/2013, PS0358/ 2016, and PI0137/2018), a grant from the Generalitat Valenciana (PROMETEO/2017/017), a SEMERGEN grant, and funds from the European Regional Development Fund (CB06/03). This research was also partially funded by EU-H2020 Grant (EAT2BENICE/H2020SFS-2016-2; Ref 728018). Study resulting from the SLT006/17/ 00246 grant, funded by the Department of Health of the Generalitat de Catalunya by the call "Acció instrumental de programes de recerca orientats en l'àmbit de la recerca i la innovació en salut". We thank CERCA Programme/Generalitat de Catalunya for institutional support. This work is partially supported by ICREA under the ICREA Academia programme. IP-G receives a grant from the Spanish Ministry of Education, Culture and Sports (FPU 17/01925). MRBL was supported by "Miguel Servet Type I" program (CP15/00028) from the ISCIII-Madrid (Spain), cofinanced by the Fondo Europeo de Desarrollo Regional-FEDER. AJG was supported by the Nora Martin Fellowship in Nutritional Sciences, the Banting \& Best Diabetes Centre Tamarack Graduate Award in Diabetes Research, the Peterborough K.M. Hunter Charitable Foundation Graduate Award and an Ontario Graduate Scholarship. PH-A was supported by a postdoctoral fellowship (Juan de la Cierva-Formación), FJCI2017-32205, funded by the Ministry of Science and Innovation. RE group has been supported by the 'Ajut 2017-2021 SGR 1717 from the Generalitat de Catalunya. DJAJ was funded by the Government of Canada through the Canada Research Chair Endowment. JK was supported by the 'FOLIUM' programme within the FUTURMed project from the Fundación Instituto de Investigación Sanitaria Illes Balears (financed by 2017 annual plan of the sustainable tourism tax and at 50\% with charge to the ESF Operational Program 2014-2020 of the Balearic Islands). JLS was funded by a Diabetes Canada Clinician Scientist Award.

\section{Conflict of interest}

AJG has done consulting work for SoLo GI Nutrition and has received an honorarium from the Soy Nutrition Institute. CWCK has received grants or research support from the Advanced Food Materials Network, Agriculture and Agri-Foods Canada (AAFC), Almond Board of California, American Peanut Council, Barilla, Canadian Institutes of Health Research (CIHR), Canola Council of Canada, International Nut and Dried Fruit Council, International Tree Nut Council Research and Education Foundation, Loblaw Brands Ltd, Pulse Canada and Unilever. He has received in-kind research support from the Almond Board of California, American Peanut Council, Barilla, California Walnut Commission, Kellogg Canada, Loblaw Companies, Nutrartis, Quaker (PepsiCo), Primo, Unico, Unilever, WhiteWave Foods/Danone. He has received travel support and/or honoraria from the American Peanut Council, Barilla, California Walnut Commission, Canola Council of Canada, General Mills, International Nut and Dried Fruit Council, International Pasta Organization, Lantmannen, Loblaw Brands Ltd, 
Nutrition Foundation of Italy, Oldways Preservation Trust, Paramount Farms, Peanut Institute, Pulse Canada, Sun-Maid, Tate \& Lyle, Unilever and White Wave Foods/Danone. He has served on the scientific advisory board for the International Tree Nut Council, International Pasta Organization, McCormick Science Institute and Oldways Preservation Trust. He is a member of the International Carbohydrate Quality Consortium (ICQC), Executive Board Member of the Diabetes and Nutrition Study Group (DNSG) of the European Association for the Study of Diabetes (EASD), is on the Clinical Practice Guidelines Expert Committee for Nutrition Therapy of the EASD and is a Director of the Toronto 3D Knowledge Synthesis and Clinical Trials foundation. DJAJ has received research grants from Loblaw Companies Ltd., the Almond Board of California, Soy Nutrition Institute (SNI), and the Canadian Institutes of Health Research (CIHR). He has received in-kind supplies for trials as a research support from the Almond board of California, Walnut Council of California, American Peanut Council, Barilla, Unilever, Unico, Primo, Loblaw Companies, Quaker (Pepsico), Pristine Gourmet, Bunge Limited, Kellogg Canada, WhiteWave Foods. He has been on the speaker's panel, served on the scientific advisory board and/or received travel support and/or honoraria from the Loblaw Companies Ltd, Diet Quality Photo Navigation (DQPN), Better Therapeutics (FareWell), Verywell, True Health Initiative (THI), Heali AI Corp, Institute of Food Technologists (IFT), Soy Nutrition Institute (SNI), Herbalife Nutrition Institute (HNI), Herbalife International, Pacific Health Laboratories, Nutritional Fundamentals for Health (NFH), the Soy Foods Association of North America, the Nutrition Foundation of Italy (NFI), the Toronto Knowledge Translation Group (St. Michael's Hospital), the Canadian College of Naturopathic Medicine, The Hospital for Sick Children, the Canadian Nutrition Society (CNS), and the American Society of Nutrition (ASN). He is a member of the International Carbohydrate Quality Consortium (ICQC). His wife, Alexandra L Jenkins, is a director and partner of INQUIS Clinical Research for the Food Industry, his 2 daughters, Wendy Jenkins and Amy Jenkins, have published a vegetarian book that promotes the use of the low glycemic index plant foods advocated here, The Portfolio Diet for Cardiovascular Risk Reduction (Academic Press/Elsevier 2020 ISBN:978-0-12-810510-8)and his sister, Caroline Brydson, received funding through a grant from the St. Michael's Hospital Foundation to develop a cookbook for one of his studies. ER has received research funding through his institution from the California Walnut Commission, Folsom, CA, USA; was a paid member of its Health Research Advisory Group; and is a nonpaid member of its Scientific Advisory Council. He has also received research support through his institution from Alexion and serves on its Scientific Advisory board, received fees for scientific presentations and travel support from Danone, and travel support from the International Nut Council. JS-S serves on the board of (and receives grant support through his institution from) the International Nut and Dried Fruit Council and the Eroski Foundation. He also serves on the Executive Committee of the Instituto Danone, Spain, and on the Scientific Committee of the Danone International Institute. He has received research support from the Patrimonio Comunal Olivarero, Spain, and Borges S.A., Spain. He receives consulting fees or travel expenses from Danone, the Eroski Foundation, the Instituto Danone Spain, and Abbot Laboratories. RE reports grants from Cerveza y Salud, Spain, Fundacion Dieta Mediterranea, Spain and Interprofesional del Vino, Spain. Also, personal fees for given lectures from Brewers of Europe, Belgium, Fundacion Cerveza y Salud, Spain, Pernaud-Ricard, Mexico, Instituto Cervantes, Alburquerque, USA; Instituto Cervantes, Milan, Italy, Instituto Cervantes, Tokyo, Japan, Lilly Laboratories, Spain, and Wine and Culinary International Forum, Spain, and non-financial support to organize a National Congress on Nutrition. Also feeding trials with product from Grand Fountain and
Uriach Laboratories, Spain. JLS has received research support from the Canadian Foundation for Innovation, Ontario Research Fund, Province of Ontario Ministry of Research and Innovation and Science, Canadian Institutes of health Research (CIHR), Diabetes Canada, PSI Foundation, Banting and Best Diabetes Centre (BBDC), American Society for Nutrition (ASN), INC International Nut and Dried Fruit Council Foundation, National Dried Fruit Trade Association, National Honey Board, International Life Sciences Institute (ILSI), Pulse Canada, Quaker, The Tate and Lyle Nutritional Research Fund at the University of Toronto, The Glycemic Control and Cardiovascular Disease in Type 2 Diabetes Fund at the University of Toronto (a fund established by the Alberta Pulse Growers), and The Nutrition Trialists Fund at the University of Toronto (a fund established by an inaugural donation from the Calorie Control Council). He has received in-kind food donations to support a randomized controlled trial from the Almond Board of California, California Walnut Commission, American Peanut Council, Barilla, Unilever/ Upfield, Unico/Primo, Loblaw Companies, Quaker, Kellogg Canada, WhiteWave Foods/Danone, and Nutrartis. He has received travel support, speaker fees and/or honoraria from Diabetes Canada, Dairy Farmers of Canada, FoodMinds LLC, International Sweeteners Association, Nestlé, Pulse Canada, Canadian Society for Endocrinology and Metabolism (CSEM), GI Foundation, Abbott, General Mills, Biofortis, ASN, Northern Ontario School of Medicine, INC Nutrition Research \& Education Foundation, European Food Safety Authority (EFSA), Comité Européen des Fabricants de Sucre (CEFS), Nutrition Communications, International Food Information Council (IFIC), Calorie Control Council, and Physicians Committee for Responsible Medicine. He has or has had ad hoc consulting arrangements with Perkins Coie LLP, Tate \& Lyle, Wirtschaftliche Vereinigung Zucker e.V., Danone, and Inquis Clinical Research. He is a member of the European Fruit Juice Association Scientific Expert Panel and Soy Nutrition Institute (SNI) Scientific Advisory Committee. He is on the Clinical Practice Guidelines Expert Committees of Diabetes Canada, European Association for the study of Diabetes (EASD), Canadian Cardiovascular Society (CCS), and Obesity Canada. He serves or has served as an unpaid scientific advisor for the Food, Nutrition, and Safety Program (FNSP) and the Technical Committee on Carbohydrates of ILSI North America. He is a member of the International Carbohydrate Quality Consortium (ICQC), Executive Board Member of the Diabetes and Nutrition Study Group (DNSG) of the EASD, and Director of the Toronto 3D Knowledge Synthesis and Clinical Trials foundation. His wife is an employee of AB InBev. All other authors declare no conflicts.

\section{Acknowledgements}

The authors would like to thank Dr. Nerea Becerra-Tomás for her assistance with this project. The authors would especially like to thank the PREDIMED-Plus participants for their enthusiastic collaboration, the PREDIMED-Plus personnel for their outstanding support, and staff of all associated primary care centers for their exceptional work. CIBEROBN, CIBERESP and CIBERDEM are initiatives of the Carlos III Health Institute, Spain. We also thank the PREDIMED-Plus Biobank Network, which is part of the National Biobank Platform of the Carlos III Health Institute for storing and managing the biological samples. Aspects of this work were presented at the 37th International Symposium on Diabetes and Nutrition 2019 in the Kerkrade, Netherlands and the Canadian Nutrition Society Annual Conference 2020, which occurred virtually.

\section{Appendix A. Supplementary data}

Supplementary data to this article can be found online at https://doi.org/10.1016/j.clnu.2021.03.016. 


\section{References}

[1] Alberti KG, Eckel RH, Grundy SM, Zimmet PZ, Cleeman JI, Donato KA, et al. Harmonizing the metabolic syndrome: a joint interim statement of the international diabetes federation task force on epidemiology and prevention; national heart, lung, and blood Institute; American heart association; World heart federation; international atherosclerosis society; and international association for the study of obesity. Circulation 2009;120:1640-5.

[2] Grundy SM. Metabolic syndrome: connecting and reconciling cardiovascular and diabetes worlds. J Am Coll Cardiol 2006;47:1093-100.

[3] Wilson PW, Kannel WB, Silbershatz H, D'Agostino RB. Clustering of metabolic factors and coronary heart disease. Arch Intern Med 1999;159:1104-9.

[4] Organization WH. Cardiovas Dis 2019.

[5] Organization WH. Diabetes 2019.

[6] Ference BA, Ginsberg HN, Graham I, Ray KK, Packard CJ, Bruckert E, et al. Lowdensity lipoproteins cause atherosclerotic cardiovascular disease. 1. Evidence from genetic, epidemiologic, and clinical studies. A consensus statement from the European Atherosclerosis Society Consensus Panel. Eur Heart J 2017;38: 2459-72.

[7] O'Donnell MJ, Xavier D, Liu L, Zhang H, Chin SL, Rao-Melacini P, et al. Risk factors for ischaemic and intracerebral haemorrhagic stroke in 22 countries (the INTERSTROKE study): a case-control study. Lancet 2010;376:112-23.

[8] Knowler WC, Barrett-Connor E, Fowler SE, Hamman RF, Lachin JM, Walker EA, et al. Reduction in the incidence of type 2 diabetes with lifestyle intervention or metformin. N Engl J Med 2002;346:393-403.

[9] Tuomilehto J, Lindstrom J, Eriksson JG, Valle TT, Hamalainen H, IlanneParikka P, et al. Prevention of type 2 diabetes mellitus by changes in lifestyle among subjects with impaired glucose tolerance. N Engl J Med 2001;344: 1343-50.

[10] American Diabetes A. 4. Lifestyle management: standards of medical care in diabetes-2018. Diabetes Care 2018;41:S38-50.

[11] Anderson TJ, Gregoire J, Pearson GJ, Barry AR, Couture P, Dawes M, et al. Canadian cardiovascular society guidelines for the management of dyslipidemia for the prevention of cardiovascular disease in the adult. Can J Cardiol 2016;32:1263-82.

[12] Arnett DK, Blumenthal RS, Albert MA, Buroker AB, Goldberger ZD, Hahn EJ, et al. ACC/AHA guideline on the primary prevention of cardiovascular disease: a report of the American College of cardiology/American heart association task force on clinical practice guidelines. Circulation 2019;140:e596-646.

[13] Diabetes Canada Clinical Practice Guidelines Expert C, Sievenpiper JL, Chan CB, Dworatzek PD, Freeze C, Williams SL. Nutrition therapy. Can J Diabetes 2018;42(Suppl 1):S64-79.

[14] Dyson PA, Twenefour D, Breen C, Duncan A, Elvin E, Goff L, et al. Diabetes UK evidence-based nutrition guidelines for the prevention and management of diabetes. Diabet Med 2018;35:541-7.

[15] Stroes ES, Thompson PD, Corsini A, Vladutiu GD, Raal FJ, Ray KK, et al. Statinassociated muscle symptoms: impact on statin therapy-European atherosclerosis society consensus panel statement on assessment, aetiology and management. Eur Heart J 2015;36:1012-22.

[16] Jenkins DJ, Kendall CW, Faulkner D, Vidgen E, Trautwein EA, Parker TL, et al. A dietary portfolio approach to cholesterol reduction: combined effects of plant sterols, vegetable proteins, and viscous fibers in hypercholesterolemia. Metabolism 2002:51:1596-604.

[17] Jenkins DJ, Kendall CW, Marchie A, Faulkner D, Vidgen E, Lapsley KG, et al. The effect of combining plant sterols, soy protein, viscous fibers, and almonds in treating hypercholesterolemia. Metabolism 2003;52:1478-83.

[18] Jenkins DJ, Kendall CW, Marchie A, Faulkner DA, Wong JM, de Souza R, et al. Effects of a dietary portfolio of cholesterol-lowering foods vs lovastatin on serum lipids and C-reactive protein. J Am Med Assoc 2003;290:502-10.

[19] Jenkins DJ, Kendall CW, Faulkner DA, Nguyen T, Kemp T, Marchie A, et al. Assessment of the longer-term effects of a dietary portfolio of cholesterollowering foods in hypercholesterolemia. Am J Clin Nutr 2006;83:582-91.

[20] Jenkins DJ, Jones PJ, Lamarche B, Kendall CW, Faulkner D, Cermakova L, et al. Effect of a dietary portfolio of cholesterol-lowering foods given at 2 levels of intensity of dietary advice on serum lipids in hyperlipidemia: a randomized controlled trial. J Am Med Assoc 2011;306:831-9.

[21] Jenkins DJ, Chiavaroli L, Wong JM, Kendall C, Lewis GF, Vidgen E, et al. Adding monounsaturated fatty acids to a dietary portfolio of cholesterol-lowering foods in hypercholesterolemia. CMAJ (Can Med Assoc J) 2010;182:1961-7.

[22] Expert Panel on Detection E. Treatment of high blood cholesterol in A. Executive summary of the third report of the national cholesterol education program (NCEP) Expert panel on detection, evaluation, and treatment of high blood cholesterol in adults (adult treatment panel III). J Am Med Assoc 2001:285:2486-97.

[23] Chiavaroli L, Nishi SK, Khan TA, Braunstein CR, Glenn AJ, Mejia SB, et al. Portfolio dietary pattern and cardiovascular disease: a systematic review and meta-analysis of controlled trials. Prog Cardiovasc Dis 2018;61:43-53.

[24] Sacks FM, Svetkey LP, Vollmer WM, Appel LJ, Bray GA, Harsha D, et al. Effects on blood pressure of reduced dietary sodium and the dietary approaches to stop hypertension (DASH) diet. DASH-sodium collaborative research group. N Engl J Med 2001:344:3-10.

[25] Chiavaroli L, Viguiliouk E, Nishi SK, Blanco Mejia S, Rahelic D, Kahleova H, et al. DASH dietary pattern and cardiometabolic outcomes: an umbrella review of systematic reviews and meta-analyses. Nutrients 2019;11.
[26] Fung TT, Chiuve SE, McCullough ML, Rexrode KM, Logroscino G, Hu FB. Adherence to a DASH-style diet and risk of coronary heart disease and stroke in women. Arch Intern Med 2008;168:713-20.

[27] Dixon LB, Subar AF, Peters U, Weissfeld JL, Bresalier RS, Risch A, et al. Adherence to the USDA Food Guide, DASH Eating Plan, and Mediterranean dietary pattern reduces risk of colorectal adenoma. J Nutr 2007;137: 2443-50.

[28] Gunther AL, Liese AD, Bell RA, Dabelea D, Lawrence JM, Rodriguez BL, et al. Association between the dietary approaches to hypertension diet and hypertension in youth with diabetes mellitus. Hypertension 2009;53:6-12.

[29] Mellen PB, Gao SK, Vitolins MZ, Goff Jr DC. Deteriorating dietary habits among adults with hypertension: DASH dietary accordance, NHANES 1988-1994 and 1999-2004. Arch Intern Med 2008;168:308-14.

[30] Martinez-Gonzalez MA, Buil-Cosiales P, Corella D, Bullo M, Fito M, Vioque J, et al. Cohort Profile: design and methods of the PREDIMED-Plus randomized trial. Int J Epidemiol 2019;48. 387-8o.

[31] Salas-Salvado J, Diaz-Lopez A, Ruiz-Canela M, Basora J, Fito M, Corella D, et al. Effect of a lifestyle intervention program with energy-restricted mediterranean diet and exercise on weight loss and cardiovascular risk factors: oneyear results of the PREDIMED-plus trial. Diabetes Care 2019;42:777-88.

[32] Martin-Moreno JM, Boyle P, Gorgojo L, Maisonneuve P, FernandezRodriguez JC, Salvini S, et al. Development and validation of a food frequency questionnaire in Spain. Int J Epidemiol 1993;22:512-9.

[33] de la Fuente-Arrillaga C, Ruiz ZV, Bes-Rastrollo M, Sampson L, MartinezGonzalez MA. Reproducibility of an FFQ validated in Spain. Publ Health Nutr 2010;13:1364-72.

[34] Fernandez-Ballart JD, Pinol JL, Zazpe I, Corella D, Carrasco P, Toledo E, et al. Relative validity of a semi-quantitative food-frequency questionnaire in an elderly Mediterranean population of Spain. Br J Nutr 2010;103:1808-16.

[35] Mataix J. Tablas de composicion de alimentos [Food composition tables). 4 ed. Granada: Universidad de Granada; 2003.

[36] Moreiras O, Carvajal A, Cabrera L, Cuadrado C. Tablas de composicion de alimentos [Food composition tables]. Madrid: Piramide; 2005.

[37] Friedewald WT, Levy RI, Fredrickson DS. Estimation of the concentration of low-density lipoprotein cholesterol in plasma, without use of the preparative ultracentrifuge. Clin Chem 1972;18:499-502.

[38] Smith Jr SC, Allen J, Blair SN, Bonow RO, Brass LM, Fonarow GC, et al., Aha, Acc, National Heart L, Blood I. AHA/ACC guidelines for secondary prevention for patients with coronary and other atherosclerotic vascular disease: 2006 update endorsed by the National Heart, Lung, and Blood Institute. J Am Coll Cardiol 2006;47:2130-9.

[39] Molina L, Sarmiento M, Penafiel J, Donaire D, Garcia-Aymerich J, Gomez M, et al. Validation of the regicor Short physical activity questionnaire for the adult population. PloS One 2017;12:e0168148.

[40] American Diabetes A. Standards of medical care in diabetes-2014. Diabetes Care 2014;37(Suppl 1):S14-80.

[41] Liu J, Sun LL, He LP, Ling WH, Liu ZM, Chen YM. Soy food consumption, cardiometabolic alterations and carotid intima-media thickness in Chinese adults. Nutr Metabol Cardiovasc Dis 2014;24:1097-104.

[42] Klingberg S, Ellegard L, Johansson I, Hallmans G, Weinehall L, Andersson H, et al. Inverse relation between dietary intake of naturally occurring plant sterols and serum cholesterol in northern Sweden. Am J Clin Nutr 2008;87: 993-1001.

[43] Jun SH, Shin WK, Kim Y. Association of soybean food intake and cardiometabolic syndrome in Korean women: Korea national health and nutrition examination survey (2007 to 2011). Diabetes Metab J 2020;44:143-57.

[44] Luo C, Zhang Y, Ding Y, Shan Z, Chen S, Yu M, et al. Nut consumption and risk of type 2 diabetes, cardiovascular disease, and all-cause mortality: a systematic review and meta-analysis. Am J Clin Nutr 2014;100:256-69.

[45] Ma L, Liu G, Ding M, Zong G, Hu FB, Willett WC, et al. Isoflavone intake and the risk of coronary heart disease in US men and women: results from 3 prospective cohort studies. Circulation 2020;141:1127-37.

[46] Mayhew AJ, de Souza RJ, Meyre D, Anand SS, Mente A. A systematic review and meta-analysis of nut consumption and incident risk of CVD and all-cause mortality. Br J Nutr 2016;115:212-25.

[47] Ras RT, van der Schouw YT, Trautwein EA, Sioen I, Dalmeijer GW, Zock PL, et al. Intake of phytosterols from natural sources and risk of cardiovascular disease in the European Prospective Investigation into Cancer and Nutrition-The Netherlands (EPIC-NL) population. Eur J Prev Cardiol 2015;22: 1067-75.

[48] Schwingshackl L, Hoffmann G. Monounsaturated fatty acids, olive oil and health status: a systematic review and meta-analysis of cohort studies. Lipids Health Dis 2014;13:154.

[49] Schwingshackl L, Lampousi AM, Portillo MP, Romaguera D, Hoffmann G, Boeing $\mathrm{H}$. Olive oil in the prevention and management of type 2 diabetes mellitus: a systematic review and meta-analysis of cohort studies and intervention trials. Nutr Diabetes 2017;7:e262.

[50] Veronese N, Solmi M, Caruso MG, Giannelli G, Osella AR, Evangelou E, et al. Dietary fiber and health outcomes: an umbrella review of systematic reviews and meta-analyses. Am J Clin Nutr 2018;107:436-44.

[51] Viguiliouk E, Glenn AJ, Nishi SK, Chiavaroli L, Seider M, Khan T, et al. Associations between dietary pulses alone or with other legumes and cardiometabolic disease outcomes: an umbrella review and updated systematic review and meta-analysis of prospective cohort studies. Adv Nutr 2019;10: S308-19. 
[52] Zhang X, Shu XO, Gao YT, Yang G, Li Q Li H, et al. Soy food consumption is associated with lower risk of coronary heart disease in Chinese women. J Nutr 2003; $133: 2874-8$

[53] AlEssa HB, Malik VS, Yuan C, Willett WC, Huang T, Hu FB, et al. Dietary patterns and cardiometabolic and endocrine plasma biomarkers in US women. Am J Clin Nutr 2017;105:432-41.

[54] Jacobs S, Boushey CJ, Franke AA, Shvetsov YB, Monroe KR, Haiman CA, et al. A priori-defined diet quality indices, biomarkers and risk for type 2 diabetes in five ethnic groups: the Multiethnic Cohort. Br J Nutr 2017:118:312-20.

[55] Tiong XT, Nursara Shahirah A, Pun VC, Wong KY, Fong AYY, Sy RG, et al. The association of the dietary approach to stop hypertension (DASH) diet with blood pressure, glucose and lipid profiles in Malaysian and Philippines populations. Nutr Metabol Cardiovasc Dis 2018;28:856-63.

[56] Mokhtari Z, Sharafkhah M, Poustchi H, Sepanlou SG, Khoshnia M, Gharavi A, et al. Adherence to the dietary approaches to stop hypertension (DASH) diet and risk of total and cause-specific mortality: results from the golestan cohort study. Int J Epidemiol 2019;48:1824-38.

[57] Hekmatdoost A, Shamsipour A, Meibodi M, Gheibizadeh N, Eslamparast T, Poustchi H. Adherence to the dietary approaches to stop hypertension (DASH) and risk of nonalcoholic fatty liver disease. Int J Food Sci Nutr 2016;67: 1024-9.

[58] Sayon-Orea C, Razquin C, Bullo M, Corella D, Fito M, Romaguera D, et al. Effect of a nutritional and behavioral intervention on energy-reduced mediterranean diet adherence among patients with metabolic syndrome: interim analysis of the PREDIMED-plus randomized clinical trial. J Am Med Assoc 2019;322:1486-99.

[59] Waterplas J, Versele V, D'Hondt E, Lefevre J, Mertens E, Charlier R, et al. A 10year longitudinal study on the associations between changes in plant-based diet indices, anthropometric parameters and blood lipids in a Flemish adult population. Nutr Diet 2020;77:196-203.

[60] Ruotolo G, Howard BV. Dyslipidemia of the metabolic syndrome. Curr Cardiol Rep 2002;4:494-500.

[61] Ma XY, Liu JP, Song ZY. Glycemic load, glycemic index and risk of cardiovascular diseases: meta-analyses of prospective studies. Atherosclerosis 2012;223:491-6.

[62] Livesey G, Taylor R, Livesey H, Liu S. Is there a dose-response relation of dietary glycemic load to risk of type 2 diabetes? Meta-analysis of prospective cohort studies. Am J Clin Nutr 2013;97:584-96.

[63] Bedard A, Corneau L, Lamarche B, Dodin S, Lemieux S. Sex differences in the impact of the mediterranean diet on LDL particle size distribution and oxidation. Nutrients 2015;7:3705-23.

[64] Bedard A, Riverin M, Dodin S, Corneau L, Lemieux S. Sex differences in the impact of the Mediterranean diet on cardiovascular risk profile. Br J Nutr 2012:108:1428-34.

[65] Viguiliouk E, Kendall CW, Kahleova H, Rahelic D, Salas-Salvado J, Choo VL, et al. Effect of vegetarian dietary patterns on cardiometabolic risk factors in diabetes: a systematic review and meta-analysis of randomized controlled trials. Clin Nutr 2019;38:1133-45.

[66] Li SS, Blanco Mejia S, Lytvyn L, Stewart SE, Viguiliouk E, Ha V, et al. Effect of plant protein on blood lipids: a systematic review and meta-analysis of randomized controlled trials. J Am Heart Assoc 2017;6.

[67] Keinan-Boker L, Peeters PH, Mulligan AA, Navarro C, Slimani N, Mattisson I, et al. Soy product consumption in 10 European countries: the European prospective investigation into cancer and nutrition (EPIC) study. Publ Health Nutr 2002;5:1217-26. 